\title{
Contribution at the Study of Neuroprotective Properties of Neuroglobin during Severe Chronic Glaucoma
}

\author{
Jean Fidèle Nnang Essone1,2, Tatiana Harly Mba Aki Angue ${ }^{3,4}$, Mounir Belmalih', \\ Rosalie Nkiéma ${ }^{5}$, Ludmila Betty Eke Ndouo4, Emmanuel Anyunzoghe66, Nathan Ekegue², \\ Félix Ovono Abessolo ${ }^{5,7}$
}

\begin{abstract}
${ }^{1}$ Department of Physiology, Faculty of Medicine and Health Sciences, University of Health Sciences, Owendo, Libreville, Gabon ${ }^{2}$ Physiological Functional Exploration and Physical Medicine Services, Owendo University Hospital Center, Owendo, Libreville, Gabon

${ }^{3}$ Department of Ophthalmology, Faculty of Medicine and Health Sciences, University of Health Sciences, Owendo, Libreville, Gabon ${ }^{4}$ Mother-Child University Hospital Center, Libreville, Gabon

${ }^{5}$ Department of Biochemistry-Chemistry, Faculty of Medicine and Health Sciences, University of Health Sciences, Owendo, Libreville, Gabon

${ }^{6}$ Department of Epidemiology, Biostatistics and Medical Informatics, Faculty of Medicine and Health Sciences, University of Health Sciences, Owendo, Libreville, Gabon

${ }^{7}$ Faculty of Pharmacy, University of Health Sciences, Owendo, Libreville, Gabon

Email: jfnnang@gmail.com, mbatai4@yahoo.fr, uss.math@yahoo.fr, ovonoabessolofelix@gmail.com
\end{abstract}

How to cite this paper: Nnang Essone, J.F., Mba Aki Angue, T.H., Belmalih, M., Nkiéma, R., Eke Ndouo, L.B., Anyunzoghe, E., Ekegue, N. and Ovono Abessolo, F. (2020) Contribution at the Study of Neuroprotective Properties of Neuroglobin during Severe Chronic Glaucoma. World Journal of Neuroscience, 10, 42-67. https://doi.org/10.4236/wjns.2020.101007

Received: December 16, 2019

Accepted: February 7, 2020

Published: February 10, 2020

Copyright (c) 2020 by author(s) and Scientific Research Publishing Inc. This work is licensed under the Creative Commons Attribution International License (CC BY 4.0).

http://creativecommons.org/licenses/by/4.0/ cc) (i) Open Access

\begin{abstract}
Introduction: The mechanisms of overexpression of neuroglobin in patients with severe glaucoma $\left(\mathrm{CG}^{+}\right)$remain hypothetical. Objective: To study the anti-apoptotic, anti-hypoxic and anti-oxidant properties of neuroglobin in $\mathrm{CG}^{+}$. Population and Methods: The visual field, as well as plasma dosage of neuroglobin $(\mathrm{CmNgb}, \mathrm{ng} / \mathrm{ml})$, hypoxia inductible factor-1alpha (CmHIF-1 $\alpha$, $\mathrm{pg} / \mathrm{ml})$, glutathione peroxidase $(\mathrm{CmGpx}, \mathrm{pg} / \mathrm{ml})$, and cytochrome $\mathrm{C}$ oxidase (CmCyt $\mathrm{C}, \mathrm{pg} / \mathrm{ml}$ ) were carried out in $45 \mathrm{CG}^{+}$and 45 controls $\left(\mathrm{CG}^{-}\right)$. The chi-2 test compared the proportions, and Spearman's test studied the correlations between quantitative variables $(\mathrm{p}<5 \%)$. Results: $\mathrm{CmNgb}$ was 4.1 in $\mathrm{CG}^{+}$, versus 2.3 in $\mathrm{CG}^{-}\left(\mathrm{p}=1.52 \times 10^{-5}\right)$. $\mathrm{CmGpx}$ was 1144.7 in $\mathrm{CG}^{+}$, versus 752.8 in $\mathrm{GC}^{-}(\mathrm{p}=0.0199)$. CmHIF-1 $\alpha$ was 4.1 in $\mathrm{CG}^{+}$, versus 3.5 in $\mathrm{CG}^{-}(\mathrm{p}=$ $0.4530)$. CmCyt $\mathrm{C}$ was 2303.26 in $\mathrm{CG}^{+}$, versus 1750.44 in $\mathrm{CG}^{-}(\mathrm{p}=0.0450)$. In $\mathrm{CG}^{+}$, there was a correlation between $\mathrm{CmNgb}$ and $\mathrm{CmGpx}(\mathrm{r}=0.417 ; \mathrm{p}=$ 0.004), CmNgb and CmHIF-1 $\alpha\left(\mathrm{r}=0.644 ; \mathrm{p}=1.8 \times 10^{-6}\right)$, and between CmHIF- $1 \alpha$ and CmGpx $(\mathrm{r}=0.447 ; \mathrm{p}=0.002)$, CmHIF- $1 \alpha$ and CmCyt C $(\mathrm{r}=$ $0.371 ; \mathrm{p}=0.012$ ). None correlation was found between $\mathrm{CmNgb}$ and $\mathrm{CmCyt} \mathrm{C}$ $(\mathrm{r}=0.126 ; \mathrm{p}=0.370)$, as well as $\mathrm{CmGpx}$ and $\mathrm{CmCyt} \mathrm{C}(\mathrm{r}=0.102 ; \mathrm{p}=0.505)$. Conclusion: The variations of apoptosis, hypoxic, and oxidative stress bio-
\end{abstract}


markers were found between $\mathrm{CG}^{+}$and $\mathrm{CG}^{-}$, as well as their correlations, suggesting that neuroglobin overexpression is related to its anti-apoptotic, anti-oxidative, and anti-hypoxic properties.

\section{Keywords}

Chronic, Severe, Glaucoma, Neuroglobin, Neuroprotective-Properties

\section{Introduction}

Chronic glaucoma (CG) is an anterior, slowly progressive ischemic optic neuropathy [1] [2] [3] [4] [5]. It is characterized by a gradual loss of axonal fibers of the optic nerve, resulting from death of retinal ganglion cells (RGC) [6] [7] [8]. It is the second leading cause of blindness in the world [9] [10] [11]. Its pathophysiology is complex, and involves two theories. The first is mechanical, and has the major effect of compression of the head of the optic nerve by intra-eye hyper pressure. The second, is vascular, and involves hypoperfusion and ischemia-hypoxia of the optic nerve [12]-[18]. Despite these theories, only intra ocular pressure (IOP) remains the commonly modified risk factor during glaucoma. This situation makes that, all current pharmacological and surgical treatments aim to reduce IOP [19] [20] [21]. However, although this approach is effective for many patients with glaucoma, a significant proportion of their visual function deteriorates inexorably. In fact, about one in eight patients with glaucoma become blind in at least one eye despite this treatment [6] [21]. In animals, experimental therapies targeting and protecting retinal ganglion cells against phenomena related to hypoperfusion of the optic nerve (ischemia, hypoxia, oxidative stress, apoptosis) have been evoked and grouped under the term neuroprotection [6] [22]-[27]. Considered as neuroprotective molecule, neuroglobin $(\mathrm{Ngb})$ is a protein belonging to the family of human globins [28]-[37]. It was discovered in 2000 by Burmester et al. [31]. It is a protein with preferential expression in the nervous system, with higher concentrations in the retinal and during optic nerve pathologies [28]-[35] [38]. Indeed, the work of Rajendram et al. had highlighted a tissue expression of neuroglobin correlated with the severity of glaucoma. This study was based on post-mortem retinal specimens from patients with a history of advanced chronic glaucoma [39]. In vivo, based on a plasma dosage in humans, Ovono et al., in 2019, had noted an overexpression of plasma neuroglobin in patients with chronic glaucoma. This elevation depended not only on the severity, but also on the duration of the disease [40]. The authors suggested, moreover to the biomarker role of this globin, that of neuroprotective of the optic nerve during primary open-angle glaucoma, but without studying its mechanisms [39] [40]. We think that, during severe chronic glaucoma in human, the overexpression of neuroglobin observed in vivo is related to its neuroprotective properties, especially, anti-apoptotic, anti-hypoxic, anti-ischemic and 
anti-oxidant. To confirm this hypothesis, we performed a plasma dosage of neuroglobin, biomarkers of hypoxia, oxidative stress, apoptosis, and analyze their correlations in patients with severe chronic glaucoma $\left(\mathrm{CG}^{+}\right)$.

\section{Population and Methods}

\subsection{Population}

This was prospective, cross-sectional and case control study, conducted from February 2018 to May 2019 in Libreville, Gabon. The recruitment of patients took place in the ophthalmology department of the University Hospital of Owendo. The conditioning and dosages of neuroglobin ( $\mathrm{Ngb}$ ), cytochrome $\mathrm{C}$ oxidase (Cyt $\mathrm{C}$ ), glutathione peroxydase (Gpx) and inducible hypoxia factor-1 alpha (HIF-1 $\alpha$ ) were performed respectively in the biochemistry laboratory of the Faculty of Medicine Owendo, and the University Hospital of Angondjé. The study population of 90 people (180 eyes) had been divided into two groups. The first had 45 people (90 eyes) with bilateral severe chronic glaucoma, followed or newly discovered (patient, $\mathrm{CG}^{+}$). The second had 45 healthy people (90 eyes), volunteers (controls, $\mathrm{CG}^{-}$), with the same socio-demographic criteria as the patients.

\subsection{Inclusion Criteria}

After obtaining informed consent, all patients aged 15 to 70 years, with bilateral severe chronic glaucoma (interrogation, visual acuity, intra ocular pressure, pachymetry, vertical cup/disk ratio, visual field), and no recent history of pathology or ocular surgery were included. Moreover, people of the same age range as patients, without ocular pathology, had been recruited (interrogation, visual acuity, intra ocular pressure, pachymetry, vertical cup/disk ratio, visual field) [40].

\subsection{Non-Inclusion Criteria}

All persons having pathologies or taking drugs likely to modify the plasma concentration of neuroglobin [40] (diseases of the nervous system other than glaucoma, taking of deferoxamine, cobalt, cinnamic and valproic acid, iron chelator, $17 \beta$-œstradiol) and those suffering of others general diseases (diabetes, hypertension, neoplasia, chronic renal failure, auto immune disease) [28] [29] [30] [40] [41] had not been included. Moreover, people on treatment with anti-oxidant activity (conversion enzyme, hypolipidemic, anti-inflammatory, chemotherapy) were not included [40] [41] [42] [43] [44]. This investigation was conducted taking into account the principles of medical ethics according to the Helsinki declaration [45]. Indeed, it has been submitted for approval by the Gabon Ethics Committee (Authorization number 014/2018/PR/SG/CNE). In addition, the authorizations of the responsibilities in charge of the units in which the study had been carried out were obtained. Furthermore, volunteers and parents of patients were assured of the confidentiality of the data collected. 


\section{Methods}

\subsection{Recruitment of Study Population}

\section{-Subjects with severe glaucoma or $\mathrm{CG}^{+}$}

Patient recruitment was carried out consecutively in the ophthalmology consultation room of the Owendo University Hospital (CHUO). The examination began with an interrogation in which socio-demographic data, personal and family history, and lifestyle habits were collected. Then, an assessment of the central thickness of the cornea, visual acuity distance, intra ocular pressure (IOP), vertical cup/disk ratio (C/D) and visual field (VF) was carried out. All patients classified as severe glaucoma $\left(\mathrm{CG}^{+}\right)$received treatment. Thus, all recent discovery $\mathrm{CG}^{+}$were put on treatment and then systematically reviewed four weeks later. On the other hand, previously diagnosed and regularly followed $\mathrm{CG}^{+}$did not change their initial treatment. Blood samples were taken during the second appointment in the recently discovered $\mathrm{CG}^{+}$, and at the first appointment for $\mathrm{CG}^{+}$diagnosed before the study.

\section{-Controls or $\mathrm{CG}^{-}$}

They were recruited voluntarily and consecutively within the general population. Participants were generally relatives of investigators or patients, medical staff and medical students. They also benefited from a blood sample, preceded by a clinical and functional evaluation carried out in the consultation room of the CHUO. This evaluation was the same that of patients (interrogation, intra ocular pressure, visual acuity distance, ratio cup/disk vertical and visual field).

During the study period, 150 people with eligibility criteria were identified, including 95 with severe glaucoma $\left(\mathrm{CG}^{+}\right)$, and 55 controls $\left(\mathrm{CG}^{-}\right)$. Of the $95 \mathrm{CG}^{+}$ recorded, 35 were not included due to high blood pressure, inflammatory pathologies $(n=10)$, diabetes $(n=5)$, smoking and alcoholic taking less than three weeks old $(n=20)$. Of the $\mathrm{CG}^{+}$included, 15 had been excluded due to refusal of blood test and unavailability. The $\mathrm{CG}^{+}$population definitively selected was 45 patients (90 eyes). Of the 55 selected controls, 45 (90 eyes) were included and nine (18 eyes) were not included for suspected glaucoma and a history of eye disease. One person was excluded from this group for refusal to take a sample. At the end of the survey, the $\mathrm{CG}^{-}$selected population was 45 patients (90 eyes). A total of 90 people (180 eyes) participated in the study (Figure 1).

The variables studied were age (in years), gender, intra ocular pressure (IOP) in $\mathrm{mmHg}$, vertical $\mathrm{C} / \mathrm{D}$ ratio (decimal scale), mean deviation or MD (Decibel, -dB) [40], plasma concentrations of neuroglobin ( $\mathrm{ng} / \mathrm{ml}$ ) [40] [41] [46] [47], glutathion peroxydase (pg/ml) [48] [49], cytochrome C oxidase (pg/ml) and HIF-1 $\alpha$ (pg/ml) [49]. The plasma concentrations of Ngb, Gpx, cytochrome C and HIF-1 $\alpha$ of controls $\left(\mathrm{CG}^{-}\right)$were considered as reference values [40] [41] [46] [47] [48].

\subsection{Diagnostic Methods and Classification of the Severity of Chronic Glaucoma}

-Determination of intra ocular pressure (IOP) 


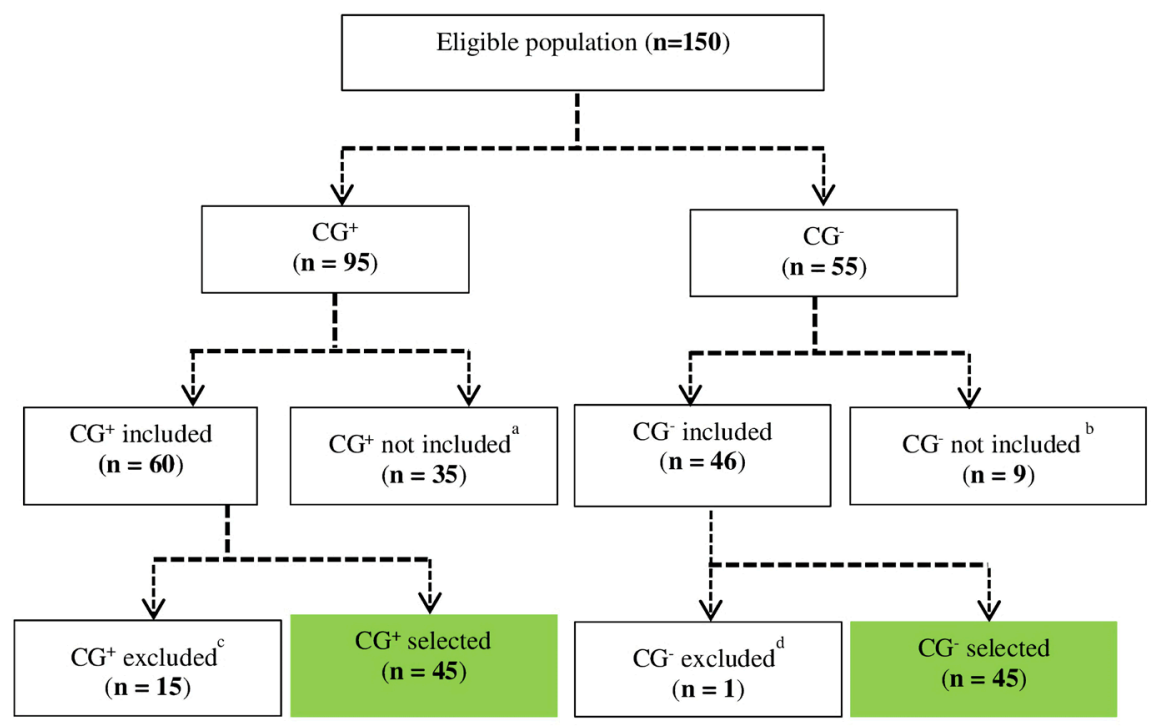

Figure 1. Flow diagram describing the selection of the study population. Legend: ${ }^{\text {a Rea- }}$ sons of non inclusion in $\mathrm{CG}^{+}$: high blood pressure, diabetes, alcoholism, smoking; ${ }^{\mathrm{b}}$ Reasons of non inclusion in $\mathrm{CG}^{-}$: suspicion of glaucoma and history of eye disease; ${ }^{\mathrm{c}}$ Reasons of exclusion in $\mathrm{CG}^{+}$: refusal to participate and unavailability; ${ }^{\mathrm{d}}$ Reasons of exclusion in $\mathrm{CG}^{-}$: Unavailability and refusal for blood test.

In each participant, IOP measurement was performed using a Goldman applanation tonometer (TAT- $100 \mathrm{~T}^{\circledR}$, TOMEY ${ }^{\mathrm{TM}}$, USA). The measurement procedure was carried out according to a protocol established during a previous study [40]. IOP was considered optimal for values below $21 \mathrm{mmHg}$ [40] [50].

\section{-Vertical Cup/disk ratio determination}

The optical disk was clinically examined with the slit lamp (TSL-7000H ${ }^{\circledR}$, $\mathrm{TOMEY}^{\mathrm{TM}}$, USA) using a Volk lens (SuperField NC ${ }^{\circledR}$, Volk $^{\mathrm{TM}}$, USA). The measurement procedure was carried out according to a protocol established by Ovono et al. study [40]. An excavation $\leq 0.3$ was considered as normal [40] [49].

\section{-Visual field evaluation method}

The automated visual field (AP- $3000^{\circledR}$, TOMEY ${ }^{\mathrm{TM}}$, USA) was practiced in both glaucoma and controls. The procedure was carried out according to a protocol established during a previous study [40]. The visual field deficit was expressed in decibel $(-\mathrm{dB})$. For this study, severe chronic glaucoma was defined by visual field with $\mathrm{MD}<-12 \mathrm{~dB}$ [40] [50] [51]. In the controls, a $\mathrm{MD}>-6 \mathrm{~dB}$ was considered as normal [40].

\subsection{Biological Methods}

\section{-Blood collection and conditioning}

Peripheral venous blood was taken after the installation of a tourniquet $\left(\mathrm{COMED}^{\circledR}\right.$, Clipcomed pro ${ }^{\mathrm{TM}}$, France). The equipment used for that was $10 \mathrm{ml}$ syringes (NORM-JECT ${ }^{\circ}, \mathrm{HSW}^{\mathrm{TM}}$, Germany) and 26-Gauge catheter (Eurofine ${ }^{\circledR}$, Euromedis $^{\mathrm{TM}}$, France). Eight milliliters of blood were collected from two previously identified dry tubes and sent to the laboratory in a cooler $\left(\right.$ Coleman $^{\mathrm{TM}}$, 
USA). Upon arrival, the plasma were centrifuged (Hettich Zentrifugen ${ }^{\circledR}$, Universal $320^{\mathrm{TM}}$, Germany), and the serum collected in cryovials (Biologix ${ }^{\circledR}$, Biolo$\mathrm{gix}^{\mathrm{TM}}$, USA), then placed in a freezer (Thermo Scientific Forma 900 Series $^{\mathrm{TM}}$, Thermo Fisher Scientific ${ }^{\circledR}$ Inc.) $-80^{\circ} \mathrm{C}$.

\section{-Plasma dosage of neuroglobine ( $\mathrm{Ngb})$}

The plasma dosage of neuroglobin was carried out by the technic ELISA (Enzyme linked immunosorbent assay). To do this, a Human NGB ELISA kit ${ }^{\mathrm{TM}}\left(\mathrm{N}^{\circ}\right.$ E-EL-H1768) was used. The manual dosage procedure was conducted according to a protocol based on previous studies [40] [46] [47] [48]. The optical density was measured on a Biorad ${ }^{\circledR}$ PR $3100^{\mathrm{TM}}$ reader. The concentration of Ngb was obtained by comparison with a standard range treated at the same time as the samples. Plasma neuroglobin $(\mathrm{CmNgb})$ concentrations were expressed in $\mathrm{ng} / \mathrm{ml}$ [49].

\section{-Plasma dosage of cytochrome C oxydase (Cyt C)}

The cytochrome $\mathrm{C}$ oxidase assay was manually performed by the ELISA (Enzyme linked immunosorbent assay) technic. It was carried out using a Human cytochrome C oxidase ELISA kit ${ }^{\mathrm{TM}}\left(\mathrm{N}^{\circ}\right.$ E-EL-H0056). The assay technic used in this study was previously described in the user manual provided by Elabscience ${ }^{\circledR}$ [49]. Plasma concentrations of cytochrome C oxidase (CmCyt C) were expressed in $\mathrm{pg} / \mathrm{ml}[49]$.

\section{-Plasma dosage of glutathione peroxidase (Gpx)}

The plasma dosage of glutathione peroxydase (the dosage of the enzyme and not of activity) was carried out by the ELISA (Enzyme linked immunosorbent assay) technic, using a Human GPX1 ELISA kit ${ }^{\mathrm{TM}}\left(\mathrm{N}^{\circ}\right.$ E-EL-H5410). The dosage procedure was done manually, following a protocol established in a previous study [46]. Plasma concentrations of $\mathrm{Gpx}(\mathrm{CmGpx})$ were expressed in $\mathrm{pg} / \mathrm{ml}$ [46] [49].

\section{-Plasma dosage of hypoxia-1 alpha inductible factor (HIF-1 $\alpha$ )}

Concerning HIF- $1 \alpha$, its plasma dosage was carried out by the ELISA (Enzyme linked immunosorbent assay) technic and using a kit Human HIF-1alpha ELISA kitTM ( $\mathrm{N}^{\circ}$ E-EL-H1277). The dosage procedure took place according to the manual dosage protocol proposed by Elabscience ${ }^{\circledR}$ [49]. Plasma concentrations of HIF-1 $\alpha$ (CmHIF-1 $\alpha$ ) were expressed in $\mathrm{pg} / \mathrm{ml}$ [49].

\subsection{Statistical Methods}

This investigation used a convenience sample, consisted of 90 people, including 45 patients with severe glaucoma $\left(\mathrm{CG}^{+}\right)$and 45 controls $\left(\mathrm{CG}^{-}\right)$. The data, upon collected, was then entered on a Microsoft Excel $2010^{\circledR}$ file and analyzed using the EPI INFO $7^{\circledR}$ software of Center for diseases control, and SPSS ${ }^{\circledR}$ Statistic 21 for $\mathrm{IBM}^{\circledR}$. The descriptive analysis was based on the calculation of means, medians, proportions and standard deviations. The comparison of proportions and means was based on the chi-square test. Spearman's test allowed us to study the correlations between quantitative variables. The relationships between quantitative and qualitative variables were analyzed by Pearson test $(\mathrm{p}<0.05)$. 


\section{Results}

\subsection{Comparison of Epidemiological and Clinical Variables between Patients with Severe Glaucoma $\left(\mathrm{CG}^{+}\right)$and Controls $\left(\mathrm{CG}^{-}\right)$}

Men accounted for $80 \%(\mathrm{n}=36 / 45)$ of $\mathrm{CG}^{+}$, and $40 \%(\mathrm{n}=18 / 45)$ of $\mathrm{CG}^{-}(\mathrm{p}=$ $\left.2.79 \times 10^{-5}\right)$. Data from age comparison and clinical variables between $\mathrm{CG}^{+}$and $\mathrm{CG}^{-}$are summarized in Table 1 . The average age of the $\mathrm{CG}^{+}$was $51.30 \pm 12.3$ years and that of the $\mathrm{CG}^{-} 41 \pm 9.5$ years $\left(\mathrm{p}=2.79 \times 10^{-5}\right)$. In $\mathrm{CG}^{+}$, the average IOP to the right eye was $21.68 \pm 12 \mathrm{mmHg}$, compared to $12.2 \pm 2.5 \mathrm{mmHg}$ in $\mathrm{CG}^{-}\left(\mathrm{p}=4.46 \times 10^{-6}\right)$. The average IOP to the left eye, in $\mathrm{CG}^{-}$was $21.55 \pm 9.5$ $\mathrm{mmHg}$, compared to $12.23 \pm 2.6 \mathrm{mmHg}$ in $\mathrm{CG}^{-}\left(\mathrm{p}=3.99 \times 10^{-8}\right)$. The vertical cup/disc ratio (C/D) to the right eye was $0.96 \pm 0.10$ in $\mathrm{CG}^{+}$, compared to $0.16 \pm$ 0.11 in $\mathrm{CG}^{-}\left(\mathrm{p}=0.1 \times 10^{-12}\right)$. This ratio to the left eye was $0.98 \pm 0.06 \mathrm{in} \mathrm{CG}^{+}$, compared to $0.15 \pm 0.10$ in $\mathrm{CG}^{-}\left(\mathrm{p}=0.1 \times 10^{-12}\right)$. The mean $\mathrm{MD}$ to the right eye in $\mathrm{CG}^{+}$was $-13.57 \pm 1.55 \mathrm{~dB}$ and $-3.45 \pm 0.87 \mathrm{~dB}^{-1 n} \mathrm{CG}^{-}\left(\mathrm{p}=0.1 \times 10^{-12}\right)$. The $\mathrm{MD}$ in the left eye was $-14.5 \pm 1.62 \mathrm{~dB}$ in $\mathrm{CG}^{+}$, and $-3.11 \pm 0.76 \mathrm{~dB}^{\text {in }} \mathrm{CG}^{-}(\mathrm{p}=$ $\left.0.1 \times 10^{-12}\right)$.

\subsection{Comparison of Biological Variables between Severe Glaucoma ( $\mathrm{CG}^{+}$) and Controls (CG-)}

The comparison of the average plasma concentration of neuroglobin ( $\mathrm{CmNgb}$ ) between $\mathrm{CG}^{+}$and $\mathrm{CG}^{-}$shows that, in the $\mathrm{CG}^{+}$, the $\mathrm{CmNgb}$ was $4.1 \pm 2.3 \mathrm{ng} / \mathrm{ml}$, versus $2.3 \pm 1.2 \mathrm{ng} / \mathrm{ml}$ in the $\mathrm{CG}^{-}\left(\mathrm{p}=1.52 \times 10^{-5}\right)$ (Figure 2$)$.

The data from the comparison of the average plasma concentration of glutathione peroxydase ( $\mathrm{CmGpx}$ ) between $\mathrm{CG}^{+}$and $\mathrm{CG}^{-}$are illustrated in Figure 3. In the $\mathrm{CG}^{+}$, the $\mathrm{CmGpx}$ was $1144.7 \pm 737.7 \mathrm{pg} / \mathrm{ml}$, compared to $752.8 \pm 506.3$ $\mathrm{pg} / \mathrm{ml}$ in the $\mathrm{CG}^{-}(\mathrm{p}=0.0199)$.

The results obtained from the comparison of average plasma concentration of the inductible factor by hypoxia-1 alpha (CmHIF-1 $\alpha$ ) between $\mathrm{CG}^{+}$and $\mathrm{CG}^{-}$ were summarized in Figure 4. The CmHif- $1 \alpha$ was $4.1 \pm 2.9 \mathrm{pg} / \mathrm{ml}$ in the $\mathrm{CG}^{+}$ and $3.5 \pm 1.9 \mathrm{pg} / \mathrm{ml}$ in the $\mathrm{CG}^{-}(\mathrm{p}=0.4530)$.

Figure 5 represents the results obtained from the comparison of average plasma concentration of cytochrome $\mathrm{C}$ oxidase $(\mathrm{CmCyt} \mathrm{C})$ between $\mathrm{CG}^{+}$and $\mathrm{GC}^{-}$. The CmCyt C was $2303.25 \mathrm{pg} / \mathrm{ml}$ in $\mathrm{GC}^{+}$versus $1750.43 \mathrm{pg} / \mathrm{ml}$ in $\mathrm{GC}^{-}(\mathrm{p}=$ 0.0450).

\subsection{Correlation between Biological Variables in Patients with Severe Glaucoma $\left(\mathrm{CG}^{+}\right)$}

The results from the analysis of the correlation between, the average plasma concentration of the inductible factor by hypoxia-1 alpha (CmHif-1 $\alpha)$ and glutathione peroxydase $(\mathrm{CmGpx})$ in $\mathrm{CG}^{+}$are illustrated in Figure 6. There was a positive correlation between CmHif- $1 \alpha$ and $\mathrm{CmGpx}$ in $\mathrm{CG}^{+}(\mathrm{r}=0.447 ; \mathrm{p}=$ $0.002)$. 
Table 1. Comparison of the averages $( \pm S D)$ of epidemiological and clinical variables between $\mathrm{CG}^{+}$and $\mathrm{CG}^{-}$.

\begin{tabular}{cccc}
\hline Variables & $\mathrm{CG}^{+}$ & $\mathrm{CG}^{-}$ & $\mathrm{p}$ \\
\hline Age (years) & $51.3(12.3)$ & $41(9.5)$ & $2.79 \times 10^{-5}$ \\
IOP $(\mathrm{mmHg})$ & & & \\
Right eye & $21.68(12)$ & $12.2(2.5)$ & $4.46 \times 10-6$ \\
Left eye & $21.55(9.9)$ & $12.23(2.6)$ & $3.99 \times 10-8$ \\
$\mathrm{C}^{\mathrm{b}} \mathrm{D}^{\mathrm{b}}$ (décimal scale) & & & \\
Right eye & $0.96(0.1)$ & $0.16(0.1)$ & $0.1 \times 10^{-12}$ \\
Left eye & $0.98(0.06)$ & $0.15(0.09)$ & $0.1 \times 10^{-12}$ \\
MD (-dB) & & & $0.1 \times 10^{-12}$ \\
Right eye & $-13.6(1.5)$ & $-3.4(0.86)$ & $0.1 \times 10^{-12}$ \\
Left eye & $-14.5(1.6)$ & $-3.1(0.76)$ & \\
\hline
\end{tabular}

${ }^{\mathrm{a}}$ Intra ocular pressure; ${ }^{\mathrm{b}} \mathrm{cup} / \mathrm{disk}$ vertical ratio; ${ }^{\mathrm{c}}$ Mean deviation.

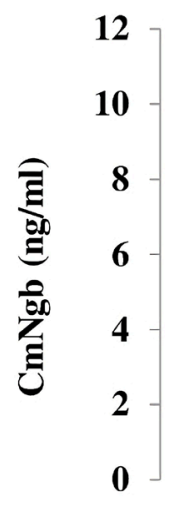

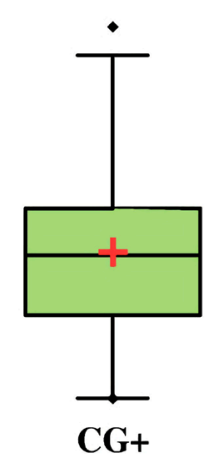

4.1

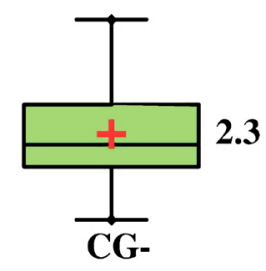

\section{Type of population}

Figure 2. Comparison of $\mathrm{CmNgb}$ between $\mathrm{CG}^{+}$and $\mathrm{CG}^{-}$.
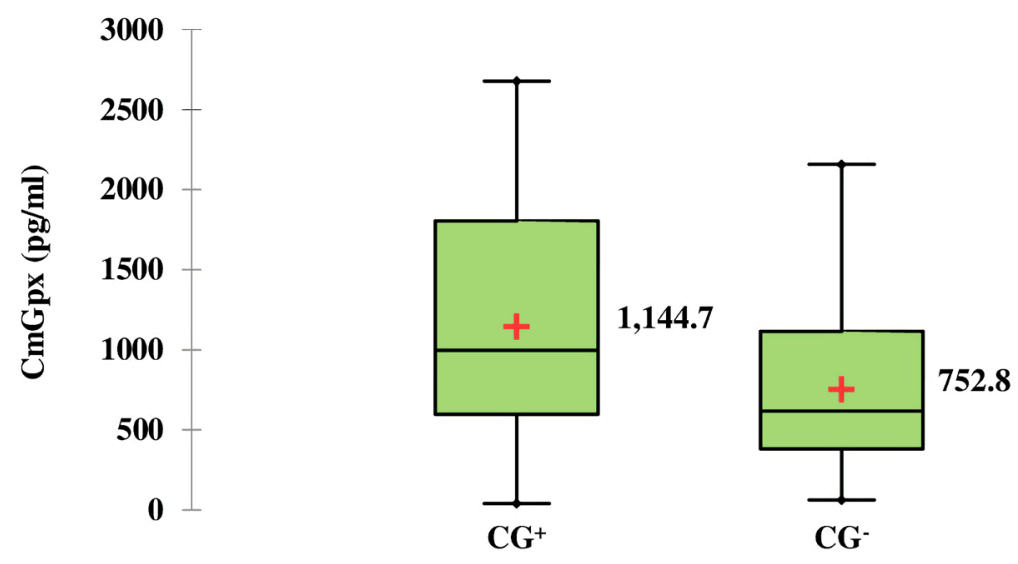

Type of population

Figure 3. Comparison of $\mathrm{CmGpx}$ between $\mathrm{CG}^{+}$and $\mathrm{CG}^{-}$. 


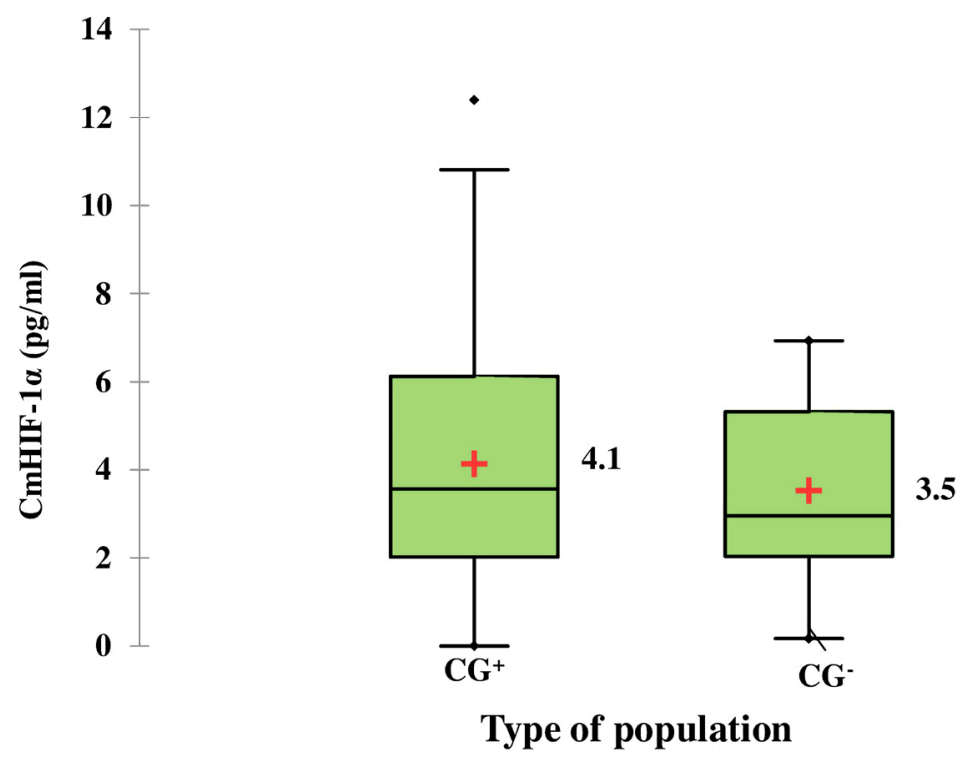

Figure 4. Comparison of CmHIF-1 $\alpha$ between $\mathrm{CG}^{+}$and $\mathrm{CG}^{-}$.
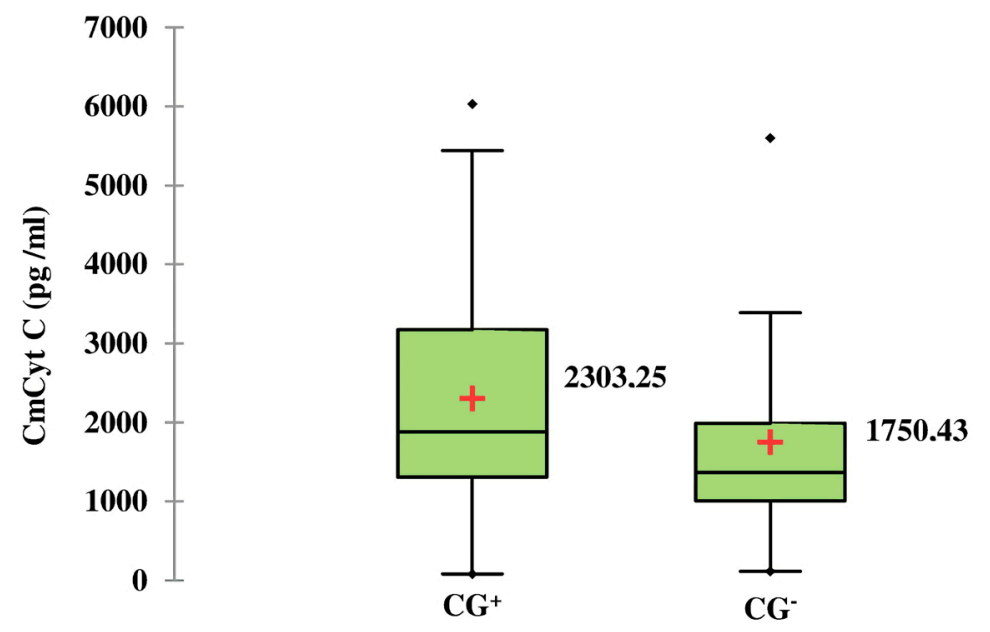

Type of population

Figure 5. Comparison of CmCyt $\mathrm{C}$ between $\mathrm{CG}^{+}$and $\mathrm{CG}^{-}$.

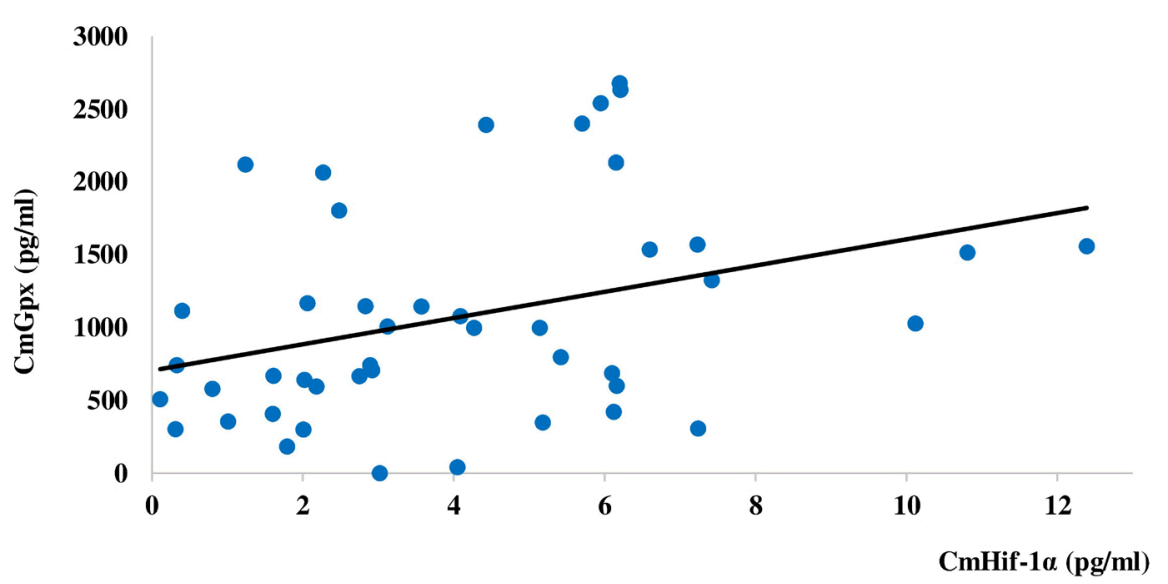

Figure 6. Correlation line between CmHif- $1 \alpha$ and $\mathrm{CmGpx}$ in $\mathrm{CG}^{+}$. 
Data from the analysis of the correlation between average plasma neuroglobin concentration $(\mathrm{CmNgb})$, and glutathione peroxydase $(\mathrm{CmGpx})$ in $\mathrm{CG}^{+}$are illustrated in Figure 7. There was a positive correlation between $\mathrm{CmNgb}$ and $\mathrm{CmGpx}$ in $\mathrm{CG}^{+}(\mathrm{r}=0.417 ; \mathrm{p}=0.004)$.

The results obtained from the analysis of the correlation between $\mathrm{CmNgb}$ and CmHif- $1 \alpha$ in $\mathrm{CG}^{+}$are represented on Figure 8. There was a positive correlation between $\mathrm{CmNgb}$ and $\mathrm{CmHif}-1 \alpha$ in the $\mathrm{CG}^{+}\left(\mathrm{r}=0.644 ; \mathrm{p}=1.8 \times 10^{-6}\right)$.

Data from the analysis of the correlation between CmHIF-1 $\alpha$ and CmCyt C are represented on Figure 9. There was a positive correlation between CmHIF-1 $\alpha$ and $\mathrm{CmCyt} C(\mathrm{r}=0.371 ; \mathrm{p}=0.012)$.

There was no correlation between $\mathrm{CmNgb}$ and CmCyt $\mathrm{C}(\mathrm{r}=0.126 ; \mathrm{p}=$ 0.370), and between CmGpx and CmCyt $C(r=0.102 ; p=0.505)$ (Figure 10, Figure 11).

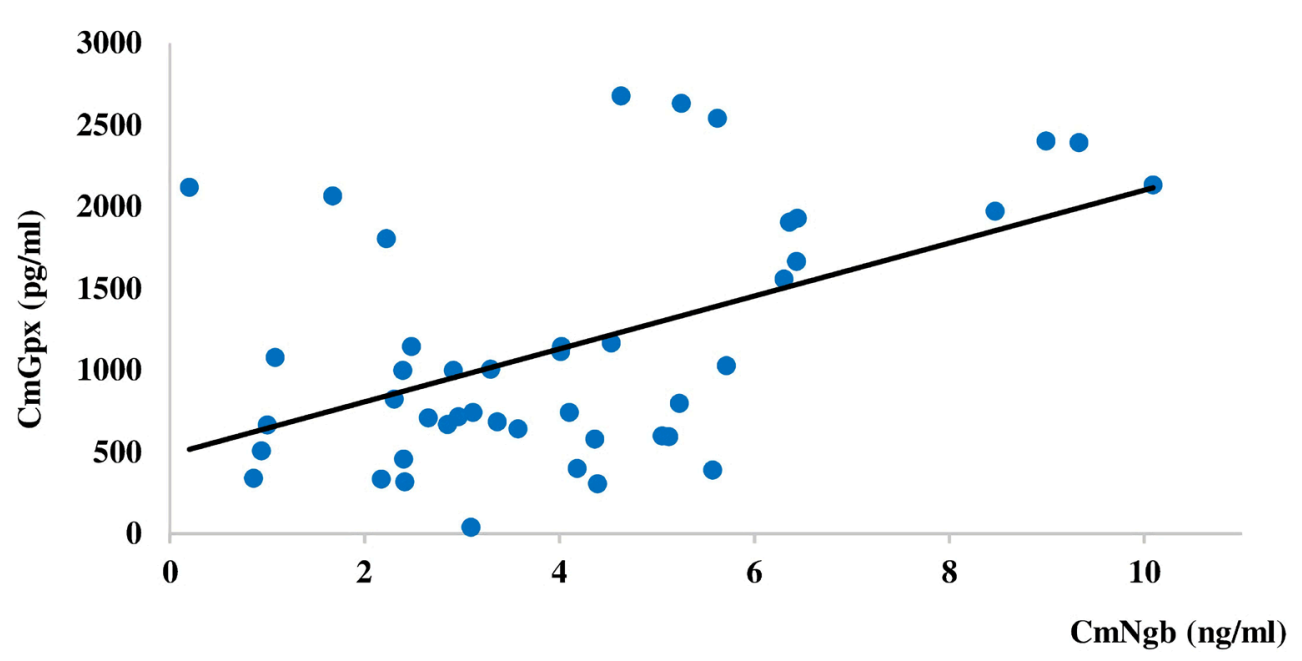

Figure 7. Correlation line between $\mathrm{CmNgb}$ and $\mathrm{CmGpx}$ in $\mathrm{CG}^{+}$.

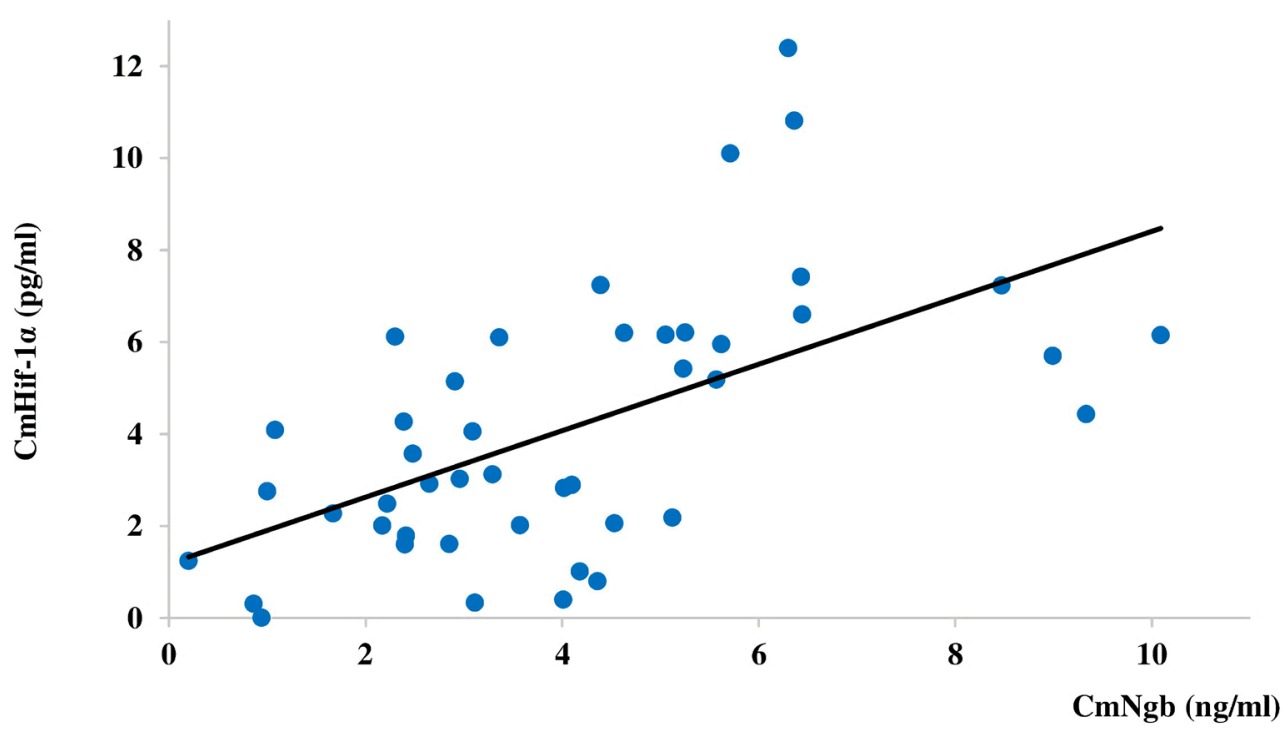

Figure 8. Correlation line between $\mathrm{CmNgb}$ and CmHIF-1 $\alpha$ in $\mathrm{CG}^{+}$. 


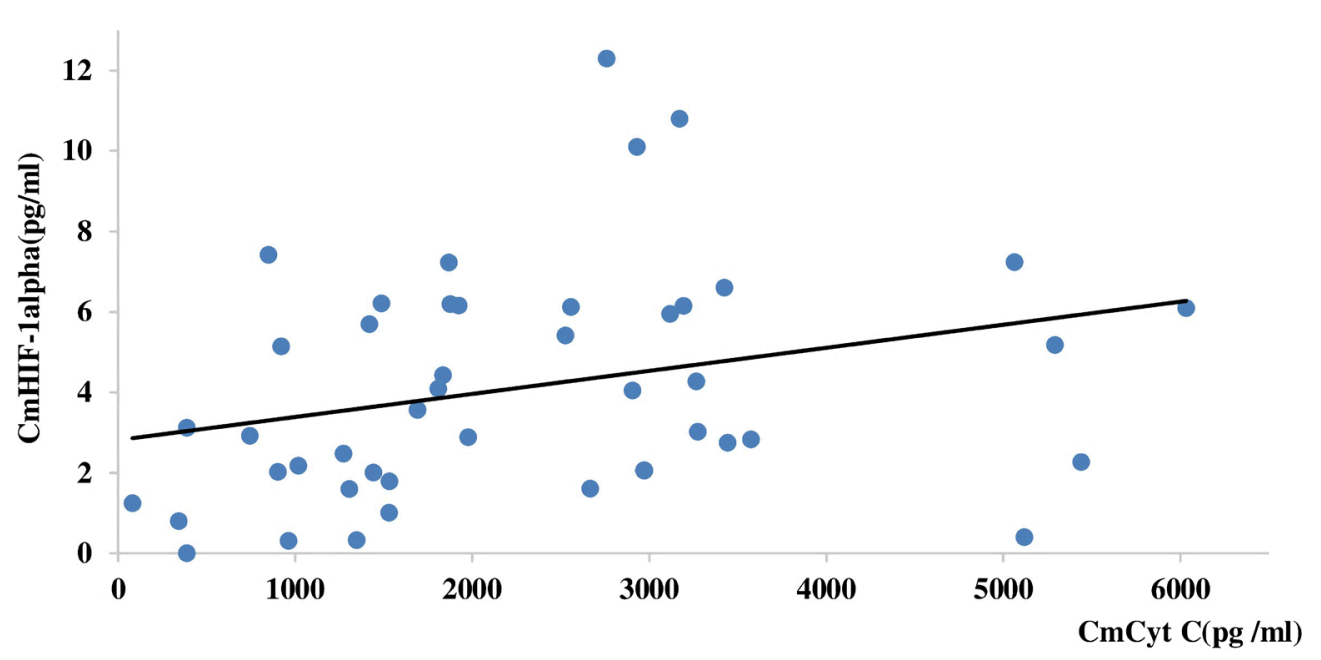

Figure 9. Correlation line between CmHIF-1alpha and $\mathrm{CmCyt} C$ in $\mathrm{CG}^{+}$.

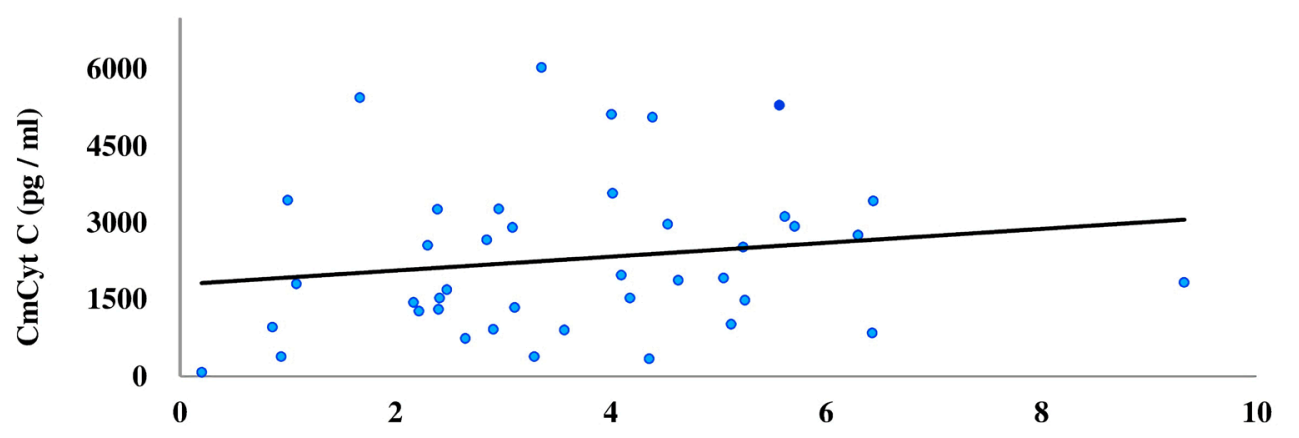

CmNgb (ng/ml)

Figure 10. Correlation line between CmHIF-1alpha and $\mathrm{CmCyt} C$ in $\mathrm{CG}^{+}$.

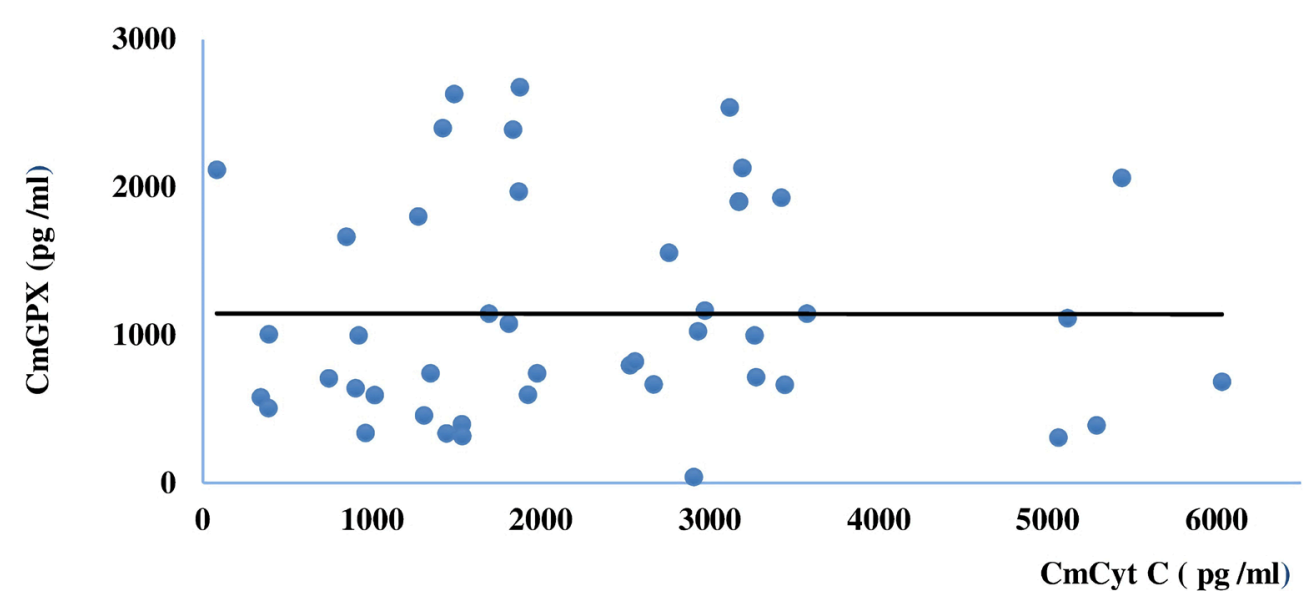

Figure 11. Correlation line between $\mathrm{CmCyt} C$ and $\mathrm{Gpx}$ in $\mathrm{CG}^{+}$.

\section{Discussion}

\subsection{Study Limits}

Chronic glaucoma (CG) is an ischemic anterior optic neuropathy, resulting in blindness by progressive loss of axonal fibers of the optic nerve [1]-[8]. A study 
conducted in human in 2019 found an overexpression of plasma neuroglobine that depended not only on the severity, but also of the evolution of chronic glaucoma, but did not explain its mechanisms [40]. We believe that during severe chronic glaucoma in vivo in human, observed neuroglobin overexpression is related to its neuroprotective properties, especially, anti-hypoxic, anti-ischemic anti-apoptotic and anti-oxidant. To confirm this hypothesis, we performed a plasma dosage of neuroglobin, biomarkers of hypoxia, apoptosis, oxidative stress, and analyzed their correlations in 45 patients with severe chronic glaucoma. During the recruitment phase of the participants, we meet several methodological difficulties. Above all, unavailability, refusal to participate and for blood test. All of these difficulties had the impact in sample size. However, despite these limitations, it appears that $\mathrm{CmNgb}$ was $4.1 \mathrm{ng} / \mathrm{ml}$ in $\mathrm{CG}^{+}$, versus 2.3 $\mathrm{ng} / \mathrm{ml}$ in $\mathrm{CG}^{-}\left(\mathrm{p}=1.52 \times 10^{-5}\right)$. The $\mathrm{CmGpx}$ was $1144.7 \mathrm{pg} / \mathrm{ml}$ in the $\mathrm{CG}^{+}$, versus $752.8 \mathrm{pg} / \mathrm{ml}$ in $\mathrm{CG}^{-}(\mathrm{p}=0.0199)$. The CmHIF- $1 \alpha$ was $4.1 \mathrm{pg} / \mathrm{ml}$ in $\mathrm{GC}^{+}$, versus $3.5 \mathrm{pg} / \mathrm{ml}$ in $\mathrm{CG}^{-}(\mathrm{p}=0.4530)$. CmCyt $\mathrm{C}$ was $2303.26 \mathrm{pg} / \mathrm{ml}$ in $\mathrm{CG}^{+}$, versus $1750.44 \mathrm{ng} / \mathrm{ml}$ in $\mathrm{CG}^{-}(\mathrm{p}=0.0450)$. In the $\mathrm{CG}^{+}$, there was a correlation between $\mathrm{cmNgb}$ and $\mathrm{CmGpx}(\mathrm{r}=0.417 ; \mathrm{p}=0.004), \mathrm{CmNgb}$ and CmHIF- $1 \alpha(\mathrm{r}=0.644 ; \mathrm{p}$ $\left.=1.8 \times 10^{-6}\right)$, and between CmHIF- $1 \alpha$ and CmGpx $(\mathrm{r}=0.447 ;(\mathrm{p}=0.002)$, CmHIF- $1 \alpha$ and CmCyt C ( $\mathrm{r}=0.371 ; \mathrm{p}=0.012)$. Conversely, there was no correlation between $\mathrm{CmNgb}$ and $\mathrm{CmCyt} \mathrm{C}(\mathrm{r}=0.126 ; \mathrm{p}=0.370)$, as well as $\mathrm{CmGpx}$ and $\mathrm{CmCyt} C(\mathrm{r}=0.102 ; \mathrm{p}=0.505)$. So, plasma concentrations of markers of hypoxia, apoptosis, oxidative stress and neuroglobin are higher in $\mathrm{CG}^{+}$compared to $\mathrm{CG}^{-}$. Furthermore, except from the cytochrome $\mathrm{C}$ oxydase, relationships were found between the different markers. In our humble opinion, these results suggest that during severe chronic glaucoma in humans in vivo, neuroglobin overexpression is related to its neuroprotective properties, especially, anti-ischemic, anti-apoptotic, anti-oxidant, and anti-hypoxic.

\subsection{Comparison of Biological Variables in Patients with Severe Glaucoma (CG+) and Controls ( $\left.\mathrm{CG}^{-}\right)$ \\ Comparison of $\mathrm{CmNgb}$ between $\mathrm{CG}^{+}$and $\mathrm{CG}^{-}$}

The $\mathrm{CmNgb}$ of the $\mathrm{CG}^{+}$was 1.8 -fold higher than that of the $\mathrm{CG}^{-}$. These results are similar to those of Rajendram et al., and Ovono et al. [39] [40]. The fist authors had found higher levels of neuroglobin in post mortem collected retinal tissues in patients with advanced chronic glaucoma, compared to healthy people. This overexpression predominated in cells with high oxygen concentration in situ. These results suggested, according to them, an anti-ischemic role of neuroglobin due to its oxygen storage capacity during advanced glaucoma [39]. Ovono et al., for their point of view, during a study conducted in human with chronic glaucoma, found plasmatic overexpression of neuroglobin correlated with the severity and duration of disease. Thus, glaucoma being a pathology in which hypoxia-ischemia processes are associated, the authors had suggested that neuroglobin had anti-ischemic properties, and had proposed it as a prognostic 
biomarker [40]. Moreover, Nnang et al., during a study with two types of populations, one of which having a stroke, and the other of healthy people (controls), had observed higher plasmatic levels of neuroglobin in patients with stroke compared to controls. According to Nnang et al., these data suggested an anti-ischemic role of neuroglobine [48]. Therefore, our results confirm that during severe chronic glaucoma in human in vivo, there is an overexpression of neuroglobin, which is linked to hypoxia-ischemia phenomena [17] [39] [40] [52] [53] [54] [55].

On the other hand, the fact that the $\mathrm{CmNgb}$ of $\mathrm{CG}^{+}$is greater than that of $\mathrm{CG}^{-}$ allows us to discuss the intensity of expression of $\mathrm{Ngb}$ during severe chronic glaucoma (CG) compared to other situations of nervous system suffering (NS). Indeed, in the $\mathrm{CG}^{+}$population of this study, $\mathrm{CmNgb}$ was 8-fold higher than that found by Ovono et al. in a study of newborns suffering of anoxo-ischemic encephalopathy syndrome $(4.09 \mathrm{ng} / \mathrm{ml}$ versus $0.50 \mathrm{ng} / \mathrm{ml})$ [46].

Moreover, Nnang et al., in a study of people with stroke had found plasmatic neuroglobine concentration 10-fold lower than our study $(4.09 \mathrm{ng} / \mathrm{ml}$ versus $0.40 \mathrm{ng} / \mathrm{ml}$ ). In that case, the results of our study support the idea that neuroglobin's expression increases not only in cases of suffering of NS in systematic way, but every more so during severe chronic glaucoma [28] [29] [30] [32] [33] [35]-[40]. Taking into account that neuroglobin overexpressed in severe chronic glaucoma in vivo, and that this elevation is function of the severity of glaucoma, our data suggest a neuroprotective role of this protein. That neuroprotection would be exercised via anti-ischemic, oxydant, hypoxic and apoptotic properties during severe chronic glaucoma.

\section{-Comparison of $\mathrm{CmGpx}$ between $\mathrm{CG}^{+}$and $\mathrm{CG}^{-}$}

During our study, we found in $\mathrm{CG}^{+}$, a $\mathrm{CmGpx} 1,5$-fold higher to that of the $\mathrm{CG}^{-}$. These results corroborate those of many other authors, including Goyal et al., as well as Rokicki et al. [43] [55] [56] [57]. Indeed, the first authors, during in a study had determined the activity levels of glutathione peroxydase (Gpx) and non-enzymatic antioxidants in the aqueous humor of patients with primary open angle glaucoma, as well as in people with cataracts. They found an increase level of Gpx in the aqueous humor of patients compared to controls. The authors had suggested the presence of oxidative stress during glaucoma [56]. The second authors had evaluated oxidative damage, as well as variations of Gpx activity in red blood cells in patients with chronic glaucoma, and in people with cataracts. In their study, they observed an increase level of Gpx activity in the patients compared to those with cataracts [57]. According to them, these data also confirmed the presence of oxidative stress during glaucoma. Because glutathione peroxydase is considered a marker of oxidative stress [58]-[73], our results confirm the idea that, there is oxidative stress during severe chronic glaucoma [16] [17] [18] [56]-[61]. Otherwise, the elevation of Gpx observed could suggest it as a prognostic biomarker of oxidative stress during this pathology [56]. Furthermore, our results support the idea that, the administration of anti- 
oxidants, additional to the conventional treatment of glaucoma would be beneficial for patients [7] [16] [22] [24] [61] [74].

\section{Comparison of CmHIF-1 $\alpha$ between $\mathrm{CG}^{+}$and $\mathrm{CG}^{-}$}

CmHIF-1 $\alpha$ in $\mathrm{CG}^{+}$was higher compared to $\mathrm{CG}^{-}\left(4.1 \pm 2.9 \mathrm{pg} / \mathrm{ml}\right.$ in the $\mathrm{CG}^{+}$ versus $3.5 \pm 1.9)(\mathrm{p}=0.4530)$. These data corroborate those of other authors, such as Tezel et al. [75]. Indeed, they had studied hypoxic stress from a post mortem analysis of retinal tissue and heads of the optic nerves of glaucoma and control eyes. They found areas of retinal tissue and the head of the optic nerve with high concentrations of HIF- $1 \alpha$, exclusively in glaucoma subjects. Based on this finding, the authors had suggested the presence of hypoxic stress during glaucoma [75]. In the same order of ideas, Resec et al. had evaluated the expression of HIF- $1 \alpha$ in the retina and head of the optic nerve of patients with advanced glaucoma. Always compared to the controls, the authors also found a great expression of HIF- $1 \alpha$ within the same areas. Thereby, they concluded that hypoxia was present during glaucoma, probably mediated by HIF-1 $\alpha$ [76]. Thus, our results confirm the presence of hypoxia during severe chronic glaucoma, as previously referred to by Childlow et al. [76] [77]. This hypoxia, according to Chen et al. [25], as well as Resec et al. [76], will be at the origin of the synthesis of HIF- $1 \alpha$. Thereafter induced HIF- $1 \alpha$ would not only play a biomarker function, but also a neuroprotective role. However, the fact that this variation is not statistically significant would likely be related to the prolonged duration of hypoxia [61]. Indeed, it has been shown that HIF- $1 \alpha$ is most often elevated only in acute, but non-chronic hypoxia, as is severe chronic glaucoma [12] [14] [17] [19] [60] [77]. An explanation for this result is related to the study population. In our sample, we have observed an important $\mathrm{MD}$ in $\mathrm{CG}^{+}$. Indeed, in $\mathrm{CG}^{+}$, the average MD was $-13.6 \mathrm{~dB}$ in the right eye, and $-14.5 \mathrm{~dB}$ on the left (normal was $-6 \mathrm{~dB}$ during the present study) [40]. In the literature, an important MD involves an advanced glaucoma, i.e. with chronic hypoxia phenomena, but not acute, associated with apoptosis [17] [19], and the inhibition of induction of HIF-1 $\alpha$ [25]. From this study, CmCyt $\mathrm{C}$ was 1.31 -fold higher in $\mathrm{CG}^{+}$, compared to $\mathrm{CG}^{-}(\mathrm{p}=$ 0.0450). According to the other authors, apoptosis phenomena are one of the principal pathophysiological elements of chronic glaucoma [17] [77] [78] [79] [80] [81]. However, according to a recent study, cytochrome C oxidase is a highly sensitive biomarker of cellular apoptosis [82] [83]. Thus, an elevation of the plasma concentration of cytochrome $\mathrm{C}$ oxidase involves intense anti-apoptotic activity. Conversely, its decrease would be related to the decline of the one. A study of Daudt II et al. [84] on the efficacy of methylene blue in the degeneration of retinal cells ganglion in relation to apoptotic phenomena had noted a greater activity of cytochrome $\mathrm{C}$ oxidase in presence of this molecule. According to the authors, this suggested the efficacy of methylene blue against apoptosis of retinal cells ganglion via a likely activation of cytochrome $\mathrm{C}$ oxidase during chronic glaucoma. Thus, these data confirmed the hypotheses on relationship between cytochrome $\mathrm{C}$ oxidase and chronic glaucoma, already observed 
by other contemporary authors [14] [15] [17]. We think that, the plasma elevation of cytochrome $\mathrm{C}$ oxidase observed in $\mathrm{CG}^{+}$confirms the presence of apoptosis phenomenon during severe chronic glaucoma in humans in vivo [14] [15] [17] [82]. Moreover, the relative difference of CmCyt $\mathrm{C}$ oxidase observed between the two groups could be related, either to the severity phenomena of glaucoma (cell necrosis, cell death), or because of the anti-apoptotic mechanisms triggered (for example, neuroglobin synthesis, cytochrome $\mathrm{C}$ oxidase itself, therapeutic factors).

\subsection{Correlation of Biological Variables in Patient with Severe Glaucoma $\left(\mathrm{CG}^{+}\right)$}

\section{Correlation of CmHif- $1 \alpha$ and $\mathrm{CmGpx}$ in $\mathrm{CG}^{+}$}

On the one hand, during this work, a positive correlation between CmHIF-1 $\alpha$ and $\mathrm{CmGpx}$ was found in the $\mathrm{CG}^{+}$. On the other hand, we noted significantly higher concentrations of HIF- $1 \alpha$ in $\mathrm{CG}^{+}$compared to $\mathrm{CG}^{-}$. These two results could have several meanings. The first would be related to HIF- $1 \alpha$. In the literature, this protein is described as one of the sub-units of the protein complex HIF-1 actively involved in hypoxic pathologies. Indeed, according to Tezel et al., as well as Resec et al., it is considered a marker of hypoxia during glaucoma [75] [76] [77]. Thus, the variation of CmHIF- $1 \alpha$ observed between $\mathrm{CG}^{+}$and $\mathrm{CG}^{-}$, in our point of view, involves the presence of hypoxia-ischemia phenomena and the anti-hypoxic role played by HIF-1 $\alpha$ during severe chronic glaucoma [75] [76] [77]. Another meaning would be related to glutathione peroxydase. This enzyme is known to be a marker of oxidative stress during reperfusion ischemia states [46], and ischemia hypoxia such as glaucoma [56] [57]. For it, according to the work of Goyal et al., Rokicki et al., as well as Marroco et al., an increase in enzyme activity, and the plasma concentration of Gpx, involves oxidative stress during glaucoma [56] [57] [58]. Taking to account the data from Weinreb et al., hypoxia is responsible of oxidative stress, that itself involves neuronal lesion, initially ischemic and then necrosis [17] [56] [57] [58] [59] [75] [76] [77] [82]. As a result, during our investigation, the variation of $\mathrm{CmGpx}$ found between $\mathrm{CG}^{+}$ and $\mathrm{CG}^{-}$, as well as the correlation between HIF-1 alpha and Gpx, suggest that during severe chronic glaucoma in human in vivo, hypoxia-ischemia phenomena are responsible for induction of oxidative stress.

\section{Correlation between $\mathrm{CmNgb}$ and $\mathrm{CmGpx}$ in $\mathrm{CG}^{+}$}

A positive correlation was found between $\mathrm{CmNgb}$ and $\mathrm{CmGpx}$ during our study. These results could have several meanings. The first concerns the neuroglobin elevation in the plasma during chronic glaucoma. Indeed, it has been established that this protein is overexpressed in hypoxia-ischemia of the nervous system, and more specifically during chronic glaucoma [39] [40] [85] [86]. Otherwise, taking into account our data, a statistically significant difference in $\mathrm{CmNgb}$ was found between $\mathrm{CG}^{+}$and $\mathrm{CG}^{-}(\mathrm{p}=0.004)$. This result, in our opinion, suggests that $\mathrm{Ngb}$ overexpression observed is related to the hypox- 
ia-ischemia phenomena already mentioned during glaucoma [17] [19] [25] [75] [76] [77] [87]. At the same time, it confirms the anti-ischemic role of this protein in relation to diseases of the nervous system [28] [29] [30] [32] [37] [42] [85], especially in chronic severe glaucoma in human [38] [39] [40] [52] [53] [54].

In parallel, another significance concerns glutathione peroxydase, which is considered by many authors as a biomarker of oxidative stress in general [58] [62]-[68] [70] [71] [73], and specifically during glaucoma [43] [56]-[61] [88] [89]. Anyway, during this survey, the CmGpx found in the $\mathrm{CG}^{+}$was 1.5 -fold higher compared to $\mathrm{CG}^{-}$. From this result, we have hypothetised the presence of oxidative stress in $\mathrm{CG}^{+}$. So, according to many authors, during chronic glaucoma, the retinal cells ganglion undergo chronic hypoxia, which will generate oxidative stress [17] [88] [89]. This oxidative stress, thereafter would induce neuroglobin synthesis [28] [90]. Thus, during our work, the positive correlation found between CmNgb and CmGpx let's say us that in patients with severe chronic glaucoma, in vivo, oxidative stress is responsible for neuroglobin induction. As a result, our data suggest that this protein exerts anti-oxidant activity during severe chronic glaucoma. This anti-oxidant activity is likely responsible for the long-term preservation of the optic nerve during this disease [28] [29] [30] [31] [32] [38] [39] [52] [53] [54].

\section{Correlation between $\mathrm{CmNgb}$ and $\mathrm{CmHif}-1 \alpha$ in $\mathrm{CG}^{+}$}

Regarding the relationship between $\mathrm{CmNgb}$ and $\mathrm{CmHif}-1 \alpha$, a positive correlation was found in $\mathrm{CG}^{+}$. This result supposes that an over-expression of Hif- $1 \alpha$ is accompanied by an overexpression of $\mathrm{Ngb}$ and conversely. Furthermore, we found higher CmHIF-1 $\alpha$ in $\mathrm{CG}^{+}$compared to $\mathrm{CG}^{-}$. According to our opinion, this suggested the presence of hypoxia in $\mathrm{CG}^{+}$. In the opinion of many authors, HIF- $1 \alpha$ is considered as mediator of neuroglobin induction in the course of nervous system hypoxia conditions, such as severe chronic glaucoma [59] [75] [85] [86]. Moreover, according to Xie et al. [28], the overexpression of neuroglobin during pathologies of the nervous system such as glaucoma is related to its anti-hypoxic properties. For this reason, we think that the relationship highlighted between CmNgb and CmHif-1 $\alpha$ during our study could mean that, in human, in the course of severe chronic glaucoma in vivo, there are hypoxia-ischemia phenomena. Thereafter, these phenomena are responsible for the overexpression of neuroglobin. Therefore, our results suggest an anti-hypoxic and anti-ischemic neuroprotective role of neuroglobin during severe chronic glaucoma in human [28]-[33] [36] [37] [38] [40].

\section{Relationship between $\mathrm{CmNgb}, \mathrm{CmGpx}$ and $\mathrm{CmHif}-1 \alpha$ in $\mathrm{CG}^{+}$}

During the present study, we found a positive correlation between and Gpx in $\mathrm{CG}^{+}$. In literature, HIF- $1 \alpha$ is considered like a biomarker of hypoxia, and Gpx that of oxidative stress [58] [59] [60] [75]. Accordingly, the relationship obtained demonstrates the presence of hypoxia and oxidative stress in the severe glaucoma in human in vivo. For this, taking into account the pathophysiology of glau- 
coma, these results suggest that in $\mathrm{CG}^{+}$, hypoxia-ischemia phenomena involve in oxidative stress activation [17] [77] [88] [89]. Similarly, a positive correlation was found between the Gpx and the Ngb. Because glutathione peroxidase is a biomarker of oxidative stress, and neuroglobin is overexpressed during ischemia-hypoxia situations of the optic nerve, we think that the positive correlation observed supposes that the induction of neuroglobin is related to oxidative stress in $\mathrm{CG}^{+}$[39] [40] [58] [60]. Regarding the precession of the induction of Ngb compared to that of oxidative stress, the result that we obtained shows that the overexpression of neuroglobin observed likely due to the oxidative stress phenomena. The existence of a positive correlation between CmNgb and CmHIF1- $\alpha$ allows us to also emit another hypothesis. Indeed, neuroglobin is considered as a biomarker of optic nerve ischemia during chronic glaucoma [39] [40] [47] [59]. Moreover, CmHIF-1 $\alpha$ has been shown to be a biomarker of hypoxia during severe chronic glaucoma. Thus, these results mean that hypoxia found during severe chronic glaucoma is likely responsible for an elevation of $\mathrm{Ngb}$, which would play its anti-hypoxic role [28] [29] [30] [31] [42] [78]. Based on these three hypotheses, we believe that during severe chronic glaucoma, there are phenomena of ischemia hypoxia and oxidative stress in the head of the optic nerve [59] [80]. These phenomena are thereafter responsible for neuroglobin overexpression [40]. This significant production of Ngb thus allows this molecule to fully play its neuroprotective role [12] [28] [29] [30] [31] [78] [79].

\section{Relationship between $\mathrm{CmNgb}, \mathrm{CmCyt} \mathrm{C}$ and $\mathrm{CmGpx}$ in $\mathrm{CG}^{+}$}

In the $\mathrm{CG}^{+}$, no correlation was found between $\mathrm{CmCyt} \mathrm{C}$ and $\mathrm{CmNgb}$ on the one hand, but also between $\mathrm{CmCyt} \mathrm{C}$ and $\mathrm{CmGpx}$ on the other. In contrast, $\mathrm{CmCyt} \mathrm{C}, \mathrm{CmGpx}$ and $\mathrm{CmNgb}$ were significantly higher in $\mathrm{CG}^{+}$compared to controls $\mathrm{CG}^{-}$. The fact that plasmatic levels of cytochrome $\mathrm{C}$ oxidase are higher in $\mathrm{CG}^{+}$makes us suggest that there are apoptosis phenomena during severe chronic glaucoma. Indeed, cytochrome $\mathrm{C}$ oxidase being a plasma biomarker of anti-apoptotic activity during chronic glaucoma, its plasmatic activity and concentration decrease with the chronic course of apoptosis towards cell necrosis, or inversely towards its disappearance [14] [15] [17] [83]. In parallel, the plasmatic overexpression of neuroglobin observed in $\mathrm{CG}^{+}$versus controls made us suppose a neuroprotective role of this protein. This neuroprotection would be exercised through the anti-hypoxic, anti-ischemic, anti-oxidant and anti-apoptotic properties [28] [29] [30] [52] [53]. Glutathione peroxydase is considered as biomarker of oxidative stress [58]-[72]. The presence of higher plasmatic levels of this protein in $\mathrm{CG}^{+}$versus $\mathrm{CG}^{-}$confirms the idea that there is oxidative stress during this pathology [16] [17] [18] [56]-[61]. Furthermore, this elevation could suggest glutathione peroxydase as a prognostic biomarker of oxidative stress during severe chronic glaucoma [56]. Thus, an explanation of the absence of correlation observed between CmCyt $\mathrm{C}$ and $\mathrm{CmNgb}$ but also between CmCyt $\mathrm{C}$ and $\mathrm{CmGpx}$ would be the fact that our sample consists mainly of severe glaucoma, probably in post apoptotic necrosis stage. Indeed, it has been shown that during chronic 
glaucoma, the apoptosis, hypoxia and oxidative stress phenomena were correlated with the progression of the disease [17] [19] [78]. These would intensify to give way to the necrosis of the retinal cells ganglion, then in fine, those of the head of the optic nerve [12] [28] [29] [30] [31] [78] [79] [82] [83]. However, the presence of higher $\mathrm{CmNgb}$ and $\mathrm{CmCyt} \mathrm{C}$ in $\mathrm{CG}^{+}$compared to $\mathrm{CG}^{-}$made us accept the hypothesis that the absence of correlation found between CmCyt $\mathrm{C}$ and $\mathrm{CmNgb}$ is would be due to the anti-apoptotic activity of the Ngb. In other words, the significant synthesis of neuroglobin would have generated an anti-apoptotic effect which is responsible for a decrease of apoptosis process in the retinal cells ganglion, and those of the head of the optic nerve. These anti-apoptotic properties of $\mathrm{Ngb}$ have already been described by several other authors [29] [30] [38] [52] [53] [55]. Another hypothesis of this result would be the fact of the presence of a significant proportion of $\mathrm{CG}^{+}$in stabilization phase under the treatment. This stabilization would be reflected biologically by the decrease of cytochrome $\mathrm{C}$ oxidase plasma concentration. The same stabilization could also explain the absence of correlation between CmCyt $\mathrm{C}$ and $\mathrm{CmGpx}$. Indeed, according many authors, the use of neuroprotective strategies would decelerate the suffering of retinal cells ganglion, and thus of oxidative stress and apoptosis [7] [12] [14] [16] [20] [22] [23] [24] [28] [29] [30] [31] [78] [79]. A cohort study including people with glaucoma and taking into account the variation of $\mathrm{CmNgb}$ according to the evolution of nerve damage under optimal therapy would be interesting. This would allow us to understand the role played by Ngb against vascular insufficiency (probably reponsible of hypoxia, then apoptosis and stress) during glaucoma, as these last lose their vision while they are on optimal treatment [82] [87]. In sum, our result corroborates the fact that during severe chronic glaucoma in vivo in humans, there are hypoxia-ischemia and apoptosis processes [12] [14] [15] [17] [25]. Those processes, at a certain duration of disease will be responsible for the synthesis of neuroglobin, via mediators such as HIF-1 alpha and cytochrome $\mathrm{C}$ oxidase. The chronically generated neuroglobin goes therefore plays an anti-apoptotic and anti-oxidant role. This chronic induction of Ngb would then influence the amplitude and progression of generating processes, and could be an explanation of the results obtained.

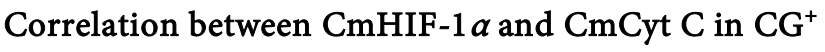

A positive correlation was found between $\mathrm{CmCyt} C$ oxidase and CmHIF-1 $\alpha$ in $\mathrm{CG}^{+}$. From this relationship, we can infer several meanings. According to recent studies, HIF- $1 \alpha$ is a specific biomarker for hypoxic phenomena and has anti-hypoxic properties during disorders of the nervous system such as glaucoma [75] [76] [77]. Furthermore, during our work, it was noted plasma concentration of HIF- $1 \alpha$ significantly higher in $\mathrm{CG}^{+}$compared to controls. In our opinion, the first meaning of this result would be the confirmation of the presence of hypoxia during severe chronic glaucoma, and suggests the neuroprotective role of HIF- $1 \alpha$ in human in vivo. The second explanation of our result is said to be related to the confirmation of the existence of apoptosis phenomena in human, 
and from this its neuroprotective role in patients with severe chronic glaucoma. Indeed, during our work, it was observed higher plasma levels of cytochrome $\mathrm{C}$ oxidase in $\mathrm{CG}^{+}$. This data confirmed the existence of apoptosis phenomena during severe chronic glaucoma. This process, as described by many authors, will be responsible for the production of anti-apoptotic mediators such as cytochrome C oxidase [17] [80] [81] [82]. In fact, cytochrome C oxidase is a plasma biomarker of anti-apoptotic activity during chronic glaucoma. Thus, its plasma activity and concentration vary with the chronic evolution of apoptosis towards cellular necrosis, or conversely towards its disappearance [14] [15] [17] [83]. The positive correlation found between HIF-1 alpha and cytochrome $\mathrm{C}$ on the one hand, and on the other hand, the variations of concentrations observed within the two groups confirm the hypothesis that, during chronic glaucoma, hypoxia is responsible of anti-hypoxic mediators such as HIF- $1 \alpha$. Thereafter, this hypoxia is itself responsible for the activation of apoptosis phenomenon.

\section{Conclusion}

This work aimed to study the anti-apoptotic, anti-hypoxic and anti-oxidant properties of neuroglobin during severe chronic glaucoma in humans in vivo. To do this, we determined biomarkers of hypoxia, apoptosis and oxidative stress in people with severe chronic glaucoma $\left(\mathrm{CG}^{+}\right)$and in controls $\left(\mathrm{CG}^{-}\right)$. At the end of our work, it appears that, compared to $\mathrm{CG}^{-}$, plasma levels of $\mathrm{Ngb}$, Gpx, cytochrome $\mathrm{C}$ oxidase and HIF-1alpha were higher in $\mathrm{CG}^{+}$. The increased plasma concentrations of these molecules reflecting their anti-ischemic, anti-hypoxic, anti-oxidant and anti-apoptotic activities respectively, as well as the observed variations between the two groups suggest the presence of apoptosis, oxidative stress and ischemia hypoxia phenomena in $\mathrm{CG}^{+}$. Otherwise, positive correlations were found in $\mathrm{CG}^{+}$, between the plasma concentration of hypoxia and oxidative stress markers on the one hand, and between neuroglobin and these markers. Even if the precession of the steps remains to be demonstrated, our results suggest that in $\mathrm{CG}^{+}$, by multiple complex processes which are being studied, hypoxia, ischemia, oxidative stress and apoptosis initially generated will induce probably in their turn, the synthesis of Ngb. The Ngb, via the amplification of the synthesis of the initial mediators, will fight against the processes at the source of the cascade. This situation, in our opinion, suggests the neuroprotective mechanisms of neuroglobin during severe chronic glaucoma. Thus, the various anti-ischemic, anti-apoptotic, anti-oxidant and anti-hypoxic mechanisms would generate the mitigation of generating processes, and could explain, at least in part, for example the absence of correlations found between apoptosis and other markers, or non-significant variation of HIF-1alpha between the two groups. Furthermore, we think that these overexpressed neuroprotective properties in the visual pathways are involved in the chronic evolution of the disease, reflecting not its natural evolution, but instead a help to the resistance capacity of retinal cells ganglion and head of the optic nerve. 


\section{Conflicts of Interest}

The authors declare no conflicts of interest regarding the publication of this paper.

\section{References}

[1] Bertaud, S., Aragno, V., Baudouin, C. and Labbé, A. (2018) Primary Open-Angle Glaucoma. La Revue de Médecine Interne, 40, 445-452. https://doi.org/10.1016/j.revmed.2018.12.001

[2] Aptel, F. (2018) Glaucomes. La revue du praticien en médecine générale, 32, 243-249.

[3] Saccà, S.C., Corazza, P., Gandolfi, S., et al. (2019) Substances of Interest That Support Glaucoma Therapy. Nutrients, 11, pii: E239. https://doi.org/10.3390/nu11020239

[4] Lusthaus, J. and Goldberg, I. (2019) Current Management of Glaucoma. The Medical Journal of Australia, 210, 180-184. https://doi.org/10.5694/mja2.50020

[5] Yang, Y., Ma, Q.Y., Yang, Y., et al. (2018) Evidence-Based Practice Guideline of Chinese Herbal Medicine for Primary Open-Angle Glaucoma. Medicine, 97, e0126. https://doi.org/10.1097/MD.0000000000010126

[6] Osborne, A., Khatib, T.Z., Songra, L., et al. (2018) Neuroprotection of Retinal Ganglion Cells by a Novel Gene Therapy Construct That Achieves Sustained Enhancement of Brain Derived Neurotrophic Factor/Tropomyosin Related Kinase Receptor-B Signaling. Cell Death \& Disease, 9, Article No. 1007.

https://doi.org/10.1038/s41419-018-1041-8

[7] Aliancy, J., Stamer, W.D. and Wirostko, B. (2017) A Review of Ritric Oxide for the Treatment of Glaucomatous Disease. Ophthalmology and Therapy, 6, 221-232. https://doi.org/10.1007/s40123-017-0094-6

[8] Basu, T., Shah, D., Das, D., Saurabh, K. and Roy, R. (2018) Multicolor Imaging for Retinal Nerve Fiber Layer Defect in Glaucoma. Indian Journal of Ophthalmology, 66, 1345-1349. https://doi.org/10.4103/ijo.IJO_30_18

[9] Kyari, F., Adekoya, B., Abdull, M.M., Mohammed, A.S. and Garba, F. (2018) The Current Status of Glaucoma and Glaucoma Care in Sub-Saharan Africa. The Asia-Pacific Journal of Ophthalmology, 7, 375-386.

[10] Onwubiko, S.N., Udeh, N.N., Nkwegu, O., Ukwu, D.O. and Nwachukwu, N.Z. (2019) Glaucoma Care in Nigeria: Is the Current Practice Poised to Tackle This Emerging Sight-Threatening Disease. International Ophthalmology, 39, 2385-2390. https://doi.org/10.1007/s10792-019-01078-9

[11] Tham, Y.C., Li, X., Wong, T.Y., Quigley, H.A., Aung, T. and Cheng, C.Y. (2014) Global Prevalence of Glaucoma and Projections of Glaucoma Burden through 2040: A Systematic Review and Meta-Analysis. Ophthalmology, 121, 2081-2090. https://doi.org/10.1016/j.ophtha.2014.05.013

[12] Ahmad, S.S. (2016) Controversies in the Vascular Theory of Glaucomatous Optic Nerve Degeneration. Journal of Ophthalmology, 5, 256-259. https://doi.org/10.1016/j.tjo.2016.05.009

[13] Ono, T., Yuki, K., Asaoka, R., et al. (2015) Glaucomatous Visual Field Defect Severity and the Prevalence of Motor Vehicle Collisions in Japanese: A Hospital/Clinic-Based Cross-Sectional Study. Journal of Ophthalmology, 2015, Article ID: 497067. https://doi.org/10.1155/2015/497067 
[14] Kaur, C., Rathnasamy, G., Foulds, W.S. and Ling, E.A. (2015) Cellular and Molecular Mechanisms of Retinal Ganglion Cell Death in Hypoxic-Ischemic Injuries. Journal of Neurology and Experimental Neuroscience, 1, 10-19. https://doi.org/10.17756/jnen.2015-003

[15] Rathnasamy, G., Sivakumar, P., Rangarajan, P., Foulds, W.S., Lings, E.A. and Kaur, C. (2014) NF- $K$ B Mediated Nitric Oxide Production and Activation of Caspase. Investigative Ophthalmology \& Visual Science, 55, 5878-5889. https://doi.org/10.1167/iovs.13-13718

[16] Rohowetz, L.J., Kraus, J. and Koulen, P. (2018) Reactive Oxygen Species-Mediated Damage of Retinal Neurons: Drug Development Targets for Therapies of Chronic Neurodegenerative of the Retina. International Journal of Molecular Sciences, 19, pii: E3362. https://doi.org/10.3390/ijms19113362

[17] Weinreb, R.N., Aung, T. and Medeiros, F.A. (2014) The Pathophysiology and Treatment of Glaucoma. JAMA, 311, 1901-1911. https://doi.org/10.1001/jama.2014.3192

[18] Yap, Z.L., Verma, S., Lee, Y.F., Ong, C., Mohla, A. and Perera, S.A. (2018) Glaucoma Related Retinal Oximetry a Technology Update. Clinical Ophthalmology, 12, 79-84. https://doi.org/10.2147/OPTH.S128459

[19] Gupta, D. and Chen, P.P. (2016) Glaucoma. American Family Physician, 93, 668-674.

[20] Marshall, L.L., Hayslett, R.L. and Stevens, G.A. (2018) Therapy for Open-Angle Glaucoma. The Consultant Pharmacist, 33, 432-445.

https://doi.org/10.4140/TCP.n.2018.432

[21] De Moraes, C.G., Liebmann, J.M. and Levin, L.A. (2017) Detection and Measurement of Clinically Meaningful Visual Field Progression in Clinical Trials for Glaucoma. Progress in Retinal and Eye Research, 56, 107-147. https://doi.org/10.1016/j.preteyeres.2016.10.001

[22] Nucci, C., Martucci, A., Giannini, C., Morrone, L.A., Bagetta, G. and Mancino, R. (2018) Neuroprotective Agents in the Management of Glaucoma. Eye, 32, 938-945. https://doi.org/10.1038/s41433-018-0050-2

[23] Gossman, C.A., Christie, J., Webster, M.K., Linn, D.M. and Linn, C.L. (2016) Neuroprotective Strategies in Glaucoma. Current Pharmaceutical Design, 22, 2178-2192. https://doi.org/10.2174/1381612822666160128144747

[24] Tian, K., Shibata-Germanos, S., Pahlitzsch, M. and Cordeiro, M.F. (2015) Current Perspective of Neuroprotection and Glaucoma. Clinical Ophthalmology, 9, 2109-2118. https://doi.org/10.2147/OPTH.S80445

[25] Cheng, L., Yu, H., Yan, N., Lai, K. and Xiang, M. (2017) Hypoxia-Inducible Factor $1 \alpha$ Target Genes Contributes to Retinal Neuroprotection. Frontiers in Cellular Neuroscience, 11, 20. https://doi.org/10.3389/fncel.2017.00020

[26] Levin, L.A. (2018) Neuroprotection in Optic Neuropathy. The Asia-Pacific Journal of Ophthalmology, 7, 246-250.

[27] Sharif, N.A. (2018) Glaucomatous Optic Neuropathy Treatment Options: The Promise of Novel Therapeutics, Techniques and Tools to Help Preserve Vision. Neural Regeneration Research, 13, 1145-1150. https://doi.org/10.4103/1673-5374.235017

[28] Xi, L.K. and Yang, S.H. (2016) Brain Globins in Physiology and Physiopathology. Medical Gas Research, 6, 154-163. https://doi.org/10.4103/2045-9912.191361

[29] Baez, E., Echeverria, V., Cabezas, R., Ávila-Rodriguez, M., Garcia-Segura, L.M. and 
Barreto, G.E. (2016) Protection by Neuroglobin Expression in Brain Pathologies. Frontiers in Neurology, 7, 146. https://doi.org/10.3389/fneur.2016.00146

[30] Ascenzi, P., Di Masi, A., Leboffe, L., et al. (2016) Neuroglobin: From Structure to Function in Health and Disease. Molecular Aspects of Medicine, 52, 1-48. https://doi.org/10.1016/j.mam.2016.10.004

[31] Burmester, T., Weich, B., Reinhard, S. and Hankeln, T. (2000) A Vertebrate Globin Expressed in the Brain. Nature, 407, 520-523. https://doi.org/10.1038/35035093

[32] Ascenzi, P., Gustincich, S. and Marino, M. (2014) Mammalian Nerve Globins in Search of Functions. IUBMB Life, 66, 268-276. https://doi.org/10.1002/iub.1267

[33] Song, X., Xu, R., Xie, F., Zhu, H., Zhu, J. and Wang, X. (2014) Hemin Offers Neuroprotection through Inducing Exogenous Neuroglobin in Focal Cerebral Hypoxic-Ischemia in Rats. International Journal of Clinical and Experimental Pathology, 7, 2163-2171.

[34] Cutrupi, S., Ferrero, G., Reineri, S., Cordero, F. and De Bortoli, M. (2014) Genomic Lens on Neuroglobin Transcription. IUBMB Life, 66, 46-51.

https://doi.org/10.1002/iub.1235

[35] Oliveira, K.C., Da Conceição, R.R., Piedade, G.C., et al. (2015) Thyroid Hormone Modulates Neuroglobin and Cytoglobin in Rat Brain. Metabolic Brain Disease, 30, 1401-1408. https://doi.org/10.1007/s11011-015-9718-5

[36] Fiocchetti, M., Cipolletti, M., Brandi, V., Polticelli, F. and Ascenzi, P. (2017) Neuroglobin and Friends. Journal of Molecular Recognition, 30, e2654.

https://doi.org/10.1002/jmr.2654

[37] Chen, F., Lu, J., Chen, F., et al. (2018) Recombinant Neuroglobin Ameliorates Early Brain Injury after Subarachnoid Hemorrhage. Neurochemistry International, 112, 219-226. https://doi.org/10.1016/j.neuint.2017.07.012

[38] Cwerman-Thibault, H., Lechauve, C., Augustin, S., et al. (2017) Neuroglobin Can Prevent or Reverse Glaucomatous Progression in DBA/2J Mice. Molecular Therapy. Methods \& Clinical Development, 5, 200-220.

https://doi.org/10.1016/j.omtm.2017.04.008

[39] Rajendram, R., Gonzalez, E. and Rao, N.A. (2010) Neuroglobin Expression Is Increased in the Retinal of Human Eyes with Chronic Glaucoma. Investigative Ophthalmology \& Visual Science, 46, 663-666.

[40] Ovono Abessolo, F., Nnang, J.F., Mba Aki, T., Matsanga Amoussa, M.D.E. and Ngou-Milama, E. (2019) Plasmatic Neuroglobin during the Primitive Open-Angle Glaucoma. Annales de Biologie Clinique, 77, 99-105.

https://doi.org/10.1684/abc.2018.1408

[41] Fiocchetti, M., Cipolletti, M., Leone, S., Ascenzi, P. and Marino, M. (2016) Neuroglobin Overexpression Induced by the $17 \beta$-Estradiol-Estrogen Receptor- $\alpha$ Pathway Reduces the Sensitivity of MCF-7 Breast Cancer Cell to Paclitaxel. IUBMB Life, 68, 645-651. https://doi.org/10.1002/iub.1522

[42] Mudjihartini, N., Nurhayati, L., Saekhu, M., Jusman, S.W., Purba, J. and Sadikin, M. (2017) Responses of Brain Tissues against Hypoxic Condition in Hemorrhagic Stroke Patients: Neuroglobin Expression in Brain Tissue and Plasma. Asian Journal of Pharmaceutical and Clinical Research, 10, 407-409. https://doi.org/10.22159/ajpcr.2017.v10i2.15971

[43] Benoist d'Azy, C., Pereira, B., Chiambaretta, F. and Dutheil, F. (2016) Oxidative and Anti-Oxidative Stress Markers in Chronic Glaucoma: A Systematic Review and Meta-Analysis. PLoS ONE, 11, e0166915. 
https://doi.org/10.1371/journal.pone.0166915

[44] Harani, H., Otmane, A., Makrelouf, M., et al. (2012) Evaluation primaire du statut antioxydant oligominéral chez le patient diabétique de type 2 algérien intérêt particulier du manganèse et du chrome. Annales de biologie Clinique, 70, 669-677.

[45] Déclaration d'Helsinki de l'Association médicale mondiale (2013) Principes éthiques applicables à la recherche médicale impliquant des êtres humains. Helsinki. http://www.wma.net/fr

[46] Nnang Essone, J.F., Ovono Abessolo, F., Tsagoulela, A., et al. (2019) Uterine Reperfusion Ischemia and Use of Elastic Tourniquet. The Journal of Bioscience and Medicine, 7, 98-119. https://doi.org/10.4236/jbm.2019.72009

[47] Ovono Abessolo, F., Atsame Minkono, P. and Nnang Essone, J.F. (2016) Neuroglobine et souffrance fœtale aigue: Y a-t-il une relation entre la neuroglobine et les marqueurs classiques de la souffrance fotale aigue? Pologne, Presses Académiques Francophones, Wroclaw, 68 p.

[48] Nnang Essone, J.F., Allognon, C., Nkiema, R., Aubin Igombé, S.R., Nzoghe Nguema, P. and Ovono Abessolo, F. (2019) Diagnostic and Prognostic Interests of Plasmatic Neuroglobin during Stroke in Adult at the Acute Phase. World Journal of Neuroscience, 9, 52-70. https://doi.org/10.4236/wjns.2019.92004

[49] Elabscience ${ }^{\circledast}$. http://www.elabscience.com

[50] Lachkar, Y., Baron, P., Berkani, M., et al. (2003) Evaluation du glaucome chronique à angle ouvert par un score de gradation analyse préliminaire. Journal Français D’Ophtalmologie, 26, 137-141.

[51] Mills, R.P., Budenz, D.L., Lee, P.P., Noecker, R.J., Walt, J.G., Siegartel, L.R., Evans, S.J. and Doyle, J.J. (2006) Categorizing the Stage of Glaucoma from Pre-Diagnosis to End-Stage Disease. American Journal of Ophthalmology, 141, 24-30. https://doi.org/10.1016/j.ajo.2005.07.044

[52] Lechauve, C., Augustin, S., Roussel, D., Sahel, J.A. and Corral-Debrinski, M. (2013) Neuroglobin Involvement in Visual Pathways through the Optic Nerve. Biochimica et Biophysica Acta, 1834, 1772-1778. https://doi.org/10.1016/j.bbapap.2013.04.014

[53] Roberts, P.A., Gaffney, E.A., Luthert, P.J., Foss, A.J. and Byrne, H.M. (2016) Retinal Oxygen Distribution and the Role of Neuroglobine. Journal of Mathematical Biology, 73, 1-38. https://doi.org/10.1007/s00285-015-0931-y

[54] Yu, Z.L., Qiu, S., Chen, X.C., et al. (2014) Neuroglobin a Potential Biological Marker of Retinal Damage Induced by LED Light. Neuroscience, 270, 158-167. https://doi.org/10.1016/j.neuroscience.2014.04.013

[55] Talwara, S. and Tyagi, G. (2015) Role of Level of Neuroglobin in Understanding the Disease Progression of Neurodegenerative Diseases. International Journal of Science and Research, 4, 1639-1640.

[56] Goyal, A., Srivastava, A., Sihota, R. and Kaur, J. (2014) Evaluation of Oxidative Stress Markers in Aqueous Humor of Primary Open Angle Glaucoma and Primary Angle Closure Glaucoma Patients. Current Eye Research, 39, 823-829. https://doi.org/10.3109/02713683.2011.556299

[57] Rokicki, W., Zalejska-Fiolkab, J., Pojda-Wilczeka, D., Kabiesza, A. and Majewskic, W. (2016) Oxidative Stress in the Red Blood Cells of Patients with Primary Open-Angle Glaucoma. Clinical Hemorheology and Microcirculation, 62, 369-378. https://doi.org/10.3233/CH-152029

[58] Marrocco, I., Altieri, F. and Peluso, I. (2017) Measurement and Clinical Significance of Biomarkers of Oxidative Stress in Humans. Oxidative Medicine and Cellular 
Longevity, 2017, Article ID: 6501046. https://doi.org/10.1155/2017/6501046

[59] Ungl, L., Pattamatta, U., Carnt, N., Wilkinson-Berka, J.L., Liew, G. and White, A.J.R. (2017) Oxidative Stress and Reactive Oxygen Species: A Review of Their Role in Ocular Disease. Clinical Science, 131, 2865-2883. https://doi.org/10.1042/CS20171246

[60] Konieczka, K., Fränkl, S., Todorova, M.G. and Henrich, P.B. (2014) Unstable Oxygen Supply and Glaucoma. Klinische Monatsblätter für Augenheilkunde, 231, 121-126. https://doi.org/10.1055/s-0033-1360242

[61] Kimura, A., Namekata, K., Guo, X., Noro, T., Harada, C. and Harada, T. (2017) Targeting Oxidative Stress for Treatment of Glaucoma and Optic Neuritis. Oxidative Medicine and Cellular Longevity, 2017, Article ID: 2817252. https://doi.org/10.1155/2017/2817252

[62] Lushchak, V.I. (2014) Free Radicals, Reactive Oxygen Species, Oxidative Stress and Its 5 Classification. Chemico-Biological Interactions, 224, 164-175. https://doi.org/10.1016/j.cbi.2014.10.016

[63] Sies, H. (2015) Oxidative Stress: A Concept in Redox Biology and Medicine. Redox Biology, 4, 180-183. https://doi.org/10.1016/j.redox.2015.01.002

[64] Xiao, G., Yu, Y., Liu, X., et al. (2014) Heterologous Expression and Characterization of Human Cellular Glutathione Peroxidase Mutants. International Union of Biochemistry and Molecular Biology, 66, 212-219. https://doi.org/10.1002/iub.1255

[65] Yin, J., Wang, B., Zhu, X., et al. (2017) The Small Glutathione Peroxyse Mimic 5P May Represent New Strategy for the Treatment of Liver Cancer. Molecules, 22, 1495. https://doi.org/10.3390/molecules22091495

[66] Xiao, B.-H., Shi, M., Chen, H., et al. (2016) Glutathione Peroxydase Level in Patients with Vitiligo: A Meta Analysis. BioMed Research International, 2016, Article ID: 3029810. https://doi.org/10.1155/2016/3029810

[67] Surai, P.F., Kochish, I.I. and Fisinin, V.I. (2018) Glutathione Peroxydases in Poultry Biology Part 1 Classification and Mechanisms of Action. Worlds Poultry Science Journal, 74, 185-198. https://doi.org/10.1017/S0043933918000284

[68] Al-Kinani, M.F. and Sayyah, S.G. (2016) Evaluate of Antioxidant Enzymes Superoxide Dismutase, Glutathione Peroxidase and Catalase Levels in Asthma Patients. Journal of Natural Sciences Research, 6, 42-48.

[69] Steinbrenner, H., Speckmann, B. and Klotz, L.O. (2016) Selenoproteins: Antioxidant Selenoenzymes and Beyond. Archives of Biochemistry and Biophysics, 595, 113-119. https://doi.org/10.1016/j.abb.2015.06.024

[70] Ighodaro, O.M. and Akinloye, O.A. (2017) First Line Defence Antioxidants-Superoxide Dismutase (SOD), Catalase (CAT) and Glutathione Peroxidase (GPX): Their Fundamental Role in the Entire Antioxidant Defence Grid. Alexandria Journal of Medicine, 54, 287-293. https://doi.org/10.1016/j.ajme.2017.09.001

[71] Bhagat, J., Ingole, B.S. and Singh, N. (2016) Glutathione S-Transferase, Catalase, Superoxide Dismustase, Glutathione Peroxidase, and Lipid Peroxidation as Biomarkers of Oxidative Stress in Snails: A Review. Biological Oceanographic Division, 13, 336-349.

[72] Haratake, M., Tachibana, Y., Emaya, Y., Sakura Yoshida, S., Fuchigami, T. and Nakayama, M. (2016) Synthesis of Nanovesicular Glutathione Peroxidase Mimics with a Selenenylsulfide-Bearing Lipid. ACS Omega, 1, 58-65.

https://doi.org/10.1021/acsomega.6b00046 
[73] Flohé, L. and Brigelius-Flohé, R. (2016) Basics and News on Glutathione Peroxidases. In: Hatfield, D.L., Schweizer, U., Tsuji, P.A. and Gladyshev, V.N., Eds., Selenium: Its Molecular Biology and Role in Human Health, 4th Edition, Springer, Berlin, 211-222. https://doi.org/10.1007/978-3-319-41283-2_17

[74] Al Owaifeer, A.M. and Al Taisan, A.A. (2018) The Role of Diet in Glaucoma: A Review of the Current Evidence. Ophthalmology and Therapy, 7, 19-31. https://doi.org/10.1007/s40123-018-0120-3

[75] Tezel, G. and Wax, M.B. (2004) Hypoxia-Inducible Factor 1 in the Glaucomatous Retina and Optic Nerve Head. Archives of Ophthalmology, 122, 1348-1356. https://doi.org/10.1001/archopht.122.9.1348

[76] Reszec, J., Zalewska, R., Bernaczyk, P. and Chyczewski, L. (2012) HIF-1 Expression in Retinal Ganglion Cells and Optic Nerve Axons in Glaucoma. Folia Histochemica et Cytobiologica, 50, 456-459. https://doi.org/10.5603/FHC.2012.0063

[77] Chidlow, G., Wood, J.P.M. and Casson, R.J. (2017) Investigations into Hypoxia and Oxidative Stress at the Optic Nerve Head in a Rat Model of Glaucoma. Frontiers in Neuroscience, 11, 478. https://doi.org/10.3389/fnins.2017.00478

[78] Cordeiro, M.F., Normando, E.M., Cardoso, J., Miodragovic, S., Jeylani, S., Davis, B.M., Guo, L., Ourselin, S., A'Hern, R. and Bloom, P.A. (2017) Real-Time Imaging of Single Neuronal Cell Apoptosis in Patients with Glaucoma. Brain, 140, 1757-1767. https://doi.org/10.1093/brain/awx088

[79] Saccà, S.C., Corazza, P., Gandolfi, S., Ferrari, D., Sukkar, S., Iorio, E.L. and Traverso, C.E. (2019) Substances of Interest That Support Glaucoma Therapy. Nutrients, 11, 239. https://doi.org/10.3390/nu11020239

[80] Wang, X., Li, Z., Bai, J., Song, W. and Zhang, F. (2019) miR-17-5p Regulates the Proliferation and Apoptosis of Human Trabecular Meshwork Cells by Targeting Phosphatase and Tensin Homolog. Molecular Medicine Reports, 19, 3132-3138. https://doi.org/10.3892/mmr.2019.9973

[81] Chen, Q., Xi, X., Zeng, Y., He, Z., Zhao, J. and Li, Y. (2019) Acteoside Inhibits Autophagic Apoptosis of Retinal Ganglion Cells to Rescue Glaucoma-Induced Optic Atrophy. Journal of Cellular Biochemistry, 120, 13133-13140. https://doi.org/10.1002/jcb.28586

[82] Rumelt, S. and Schreib, S. (2018) Why Do Patients with Controlled Glaucoma Continue to Lose Their Vision? In: Rumelt, S., Ed., Causes and Coping with Visual Impairment and Blindness, IntechOpen, London, 23-32. https://doi.org/10.5772/intechopen.79764

[83] Radhakrishnan, J., Origenes, R., Littlejohn, G., Nikolich, S., Choi, E., Smite, S., Lamoureux, L., Baetiong, A., Shah, M. and Gazmuri, R.J. (2017) Plasma Cytochrome C Detection Using a Highly Sensitive Electrochemiluminescence Enzyme-Linked Immunosorbent Assay. Biomarker Insights, 12, 1-10.

https://doi.org/10.1177/1177271917746972

[84] Daudt II, D.R., Mueller, B., Park, Y.H., Wen, Y. and Yorio, T. (2012) Methylene Blue Protects Primary Rat Retinal Ganglion Cells from Cellular Senescence. Investigative Ophthalmology \& Visual Science, 53, 4657-4667.

https://doi.org/10.1167/iovs.12-9734

[85] Xue, L., Chen, H., Lua, K., Huanga, J., Duana, H. and Zhao, Y. (2017) Clinical Significance of Changes in Serum Neuroglobin and HIF-1 $\alpha$ Concentrations during the Early-Phase of Acute Ischemic Stroke. Journal of the Neurological Sciences, 375, 52-57. https://doi.org/10.1016/j.jns.2017.01.039

[86] Liu, N., Yu, Z. and Xiang, S. (2012) Transcriptional Regulation Mechanisms of Hy- 
poxia-Induced Neuroglobin Gene Expression. Biochemical Journal, 443, 153-164. https://doi.org/10.1042/BJ20111856

[87] Ster, A.M., Popp, R.A., Petrisor, F.M., Stan, C. and Pop, V.I. (2014) The Role of Oxidative Stress and Vascular Insufficiency in Primary Open Angle Glaucoma. Clujul Medical, 87, 143-146. https://doi.org/10.15386/cjmed-295

[88] Abu-Amero, K.K., Kondkar, A.A., Mousa, A., Osman, E.A. and Al-Obeidan, S.A. (2013) Decreased Total Antioxidants in Patients with Primary Open Angle Glaucoma. Current Eye Research, 38, 959-964. https://doi.org/10.3109/02713683.2013.794246

[89] Sorkhabi, R., Ghorbanihaghjo, A., Javadzadeh, A., Rashtchizadeh, N. and Moharrery, M. (2011) Oxidative DNA Damage and Total Antioxidant Status in Glaucoma Patients. Molecular Vision, 17, 41-46.

[90] Fiocchetti, M., Cipolletti, M., Leone, S., Naldini, A., Carraro, F., et al. (2016) Neuroglobin in Breast Cancer Cells: Effect of Hypoxia and Oxidative Stress on Protein Level, Localization, and Anti-Apoptotic Function. PLOS ONE, 11, e0154959. https://doi.org/10.1371/journal.pone.0154959 